\title{
Steam reforming of methanol on PdZn near-surface alloys on Pd(1 11 1) and Pd foil studied by in-situ XPS, LEIS and PM-IRAS
}

\author{
C. Rameshan ${ }^{\mathrm{a}, \mathrm{b}}$, C. Weilach ${ }^{\mathrm{c}}$, W. Stadlmayr ${ }^{\mathrm{a}}$, S. Penner ${ }^{\mathrm{a}}$, H. Lorenz $z^{\mathrm{a}}$, M. Hävecker ${ }^{\mathrm{b}}$, R. Blume ${ }^{\mathrm{b}}$, \\ T. Rocha ${ }^{\mathrm{b}}$, D. Teschner ${ }^{\mathrm{b}}$, A. Knop-Gericke ${ }^{\mathrm{b}}$, R. Schlögl', D. Zemlyanov ${ }^{\mathrm{d}}$, N. Memmel ${ }^{\mathrm{a}}$, G. Rupprechter ${ }^{\mathrm{c}}$, \\ B. Klötzer ${ }^{\mathrm{a}, *}$ \\ ${ }^{a}$ Institute of Physical Chemistry, University of Innsbruck, Innrain 52a, A-6020 Innsbruck, Austria \\ ${ }^{b}$ Department of Inorganic Chemistry, Fritz-Haber-Institute of the Max-Planck-Society, Faradayweg 4-6, \\ D-14195 Berlin, Germany \\ 'Institute of Materials Chemistry, Vienna University of Technology, Veterinärplatz 1, \\ A-1210 Vienna, Austria \\ ${ }^{\mathrm{d}}$ Purdue University, Birck Nanotechnology Center, 1205 West State Street, West Lafayette, IN 47907-2057, USA \\ *Corresponding author: e-mail Bernhard.Kloetzer@uibk.ac.at,
}

Received 7 June 2010; revised 1 September 2010; accepted 4 September 2010. Available online 14 October 2010.

\begin{abstract}
The $\mathrm{CO}_{2}$-selectivity in methanol steam reforming was investigated for a "multilayer" PdZn 1:1 surface alloy (thickness of $\sim 1.3 \mathrm{~nm}$ ) and for a subsurface-Zn diluted "monolayer" PdZn surface alloy, both exhibiting a 1:1 composition in the surface layer. Despite having almost the same surface layer stoichiometry, these two types of near-surface alloys exhibit different corrugations and electronic structures. The $\mathrm{CO}_{2}$-selective multilayer alloy features a lowered density of states close to the Fermi edge and surface ensembles of PdZn exhibiting a "Zn-up/Pd-down" corrugation, acting as bifunctional active sites both for reversible water activation as $\mathrm{ZnOH}$ and for reaction of methanol (via formaldehyde $+\mathrm{ZnOH}$ ) toward $\mathrm{CO}_{2}$.

The thermochemical stability limit of the multilayer alloy at around $573 \mathrm{~K}$ was determined in-situ at elevated pressures of water, methanol and CO, applying in-situ XPS, PM-IRAS spectroscopy, LEIS and AES. Above $573 \mathrm{~K}$, the coordination of the surface 1:1 PdZn layer with subsurface$\mathrm{Zn}$ gradually decreased by bulk diffusion of $\mathrm{Zn}$ "escaping" from the second and deeper layers, resulting in a transition from the $\mathrm{CO}_{2}$-selective PdZn "multilayer" state to the unselective "monolayer" state, which only catalyses methanol dehydrogenation to CO.
\end{abstract}

Keywords: PdZn near-surface alloy, $\mathrm{Pd}(111)$, Pd foil, methanol dehydrogenation, methanol steam reforming, water activation, high-pressure XPS, in-situ polarization-modulation IR

\section{Introduction}

Complementing recent advances in $\mathrm{Cu} / \mathrm{ZnO}$-based methanol steam reforming "MSR" catalysis, Iwasa et al. have identified palladium nanoparticles supported on $\mathrm{ZnO}$, $\mathrm{Ga}_{2} \mathrm{O}_{3}$ and $\mathrm{In}_{2} \mathrm{O}_{3}$ as highly selective for MSR [1]. These catalysts have in common that bimetallic Pd-M nanoparticles are formed upon $\mathrm{H}_{2}$ treatment. Especially 1:1 PdZn nanoparticles supported on $\mathrm{ZnO}$ offer the advantage of higher thermal and chemical stability [1,2] than their $\mathrm{Cu}$ counterpart, giving rise to better long-term stability and less deactivation with time-on-stream [3].
Empirically, the presence of intermetallic particles of a specific composition, corresponding e.g. to the stable $\mathrm{Pd}_{1} \mathrm{Zn}_{1}$ or $\mathrm{Pd}_{2} \mathrm{Ga}$ bulk phases, has been shown to be highly beneficial for the desired selectivity of the MSR process $\mathrm{CH}_{3} \mathrm{OH}+\mathrm{H}_{2} \mathrm{O} \rightarrow \mathrm{CO}_{2}+3 \mathrm{H}_{2}$ [1] and for suppression of the methanol dehydrogenation reaction $\mathrm{CH}_{3} \mathrm{OH} \rightarrow \mathrm{CO}+2 \mathrm{H}_{2}$. This result is very interesting, but also raises several questions regarding details of the action of the respective "isolated" bimetallic surfaces (i.e. without contact to the respective oxidic support under realistic catalytic conditions). Most importantly, the "working catalyst" surface may be substantially affected by chemical and/or thermal modification, or segregation effects. Under realistic steady- 
state reaction conditions a specific dynamic surface state of PdZn can be expected, directly adapting to the thermodynamic limitations resulting from the chosen gas phase.

In this work we present a detailed model catalyst study of near-surface PdZn alloys on both $\mathrm{Pd}(111)$ and polycrystalline $\mathrm{Pd}$ samples. The model approach using extended bimetallic surfaces under close-to-real conditions, in combination with advanced in-situ spectroscopic techniques (X-ray photoelectron spectroscopy (XPS) and polarization-modulation infrared absorption spectroscopy (PMIRAS) in the mbar range) allows to elucidate the correlation between catalytic selectivity, details of the bimetallic coordination on and near the surface ("ligand effect") and surface composition ("ensemble effect"). Furthermore, the alloy stability under ambient-pressure reaction conditions can be examined in a direct manner.

Concerning the already existing knowledge, a number of studies focused on $\mathrm{ZnO}$-supported $\mathrm{PdZn}$ catalysts and $\mathrm{Pd}-\mathrm{Zn}$ intermetallic systems. Reduction of $\mathrm{Pd}$ supported on $\mathrm{ZnO}$ in $\mathrm{H}_{2}$ at $\mathrm{T} \sim 523 \mathrm{~K}$ leads to the formation of particularly stable 1:1 PdZn nanoparticles crystallizing in the tetragonal AuCu-type lattice $[1,2,4]$. Both experimental and theoretical studies have already addressed the important issue of surface composition and segregation trends of the Pd-Zn intermetallic system (near-surface alloy on a single crystal and 1:1 PdZn nanoparticles on $\mathrm{ZnO}$ [5-11]) as a function of the $\mathrm{Zn}: \mathrm{Pd}$ ratio ( $\mathrm{Zn}$ coverage) and the temperature. For the specific 1:1 stoichiometry, DFT calculations identified a 1:1 ratio of $\mathrm{Pd}$ and $\mathrm{Zn}$ as the most stable configuration also in the surface layer, at least from the viewpoint of surface/bulk energetics that were not affected by high gas pressures or elevated temperature $[8,10]$. Related experimental studies of the $\mathrm{Zn} / \mathrm{Pd}(111)$ system using XPS reported different stages of the alloying process as a function of temperature, among them the formation of the theoretically predicted $1: 1$ surface composition $[5,11,12]$. Studies performed by some of us revealed tetragonal $\mathrm{Au}-$ Cu-type PdZn nanoparticles [2] and a tetragonal PdZn nearsurface alloy formed on $\operatorname{Pd}(111)$ at elevated temperatures and high $\mathrm{Zn}$ coverages beyond $5 \mathrm{ML}$, which closely resembled the active tetragonal bulk alloy state [6]. Since the electronic structure of the $1: 1 \mathrm{PdZn}$ alloy is similar to that of metallic copper, a phenomenological interpretation of the observed analogous catalytic performance of both $\mathrm{Cu}$ and PdZn was suggested [5,11-15]. A general concept involving the cooperative action of the $\mathrm{Cu}$-like electronic structure of an extended PdZn "multilayer" surface alloy, in combination with a corrugated 1:1 PdZn surface layer, being capable of efficient water activation, was presented recently by Rameshan et al. [14]. In the current work we focus on a more detailed characterization of the most active/selective PdZn bimetallic surface state. Details of its high-pressure thermochemical stability and its mechanistic role in the selective MSR process towards $\mathrm{CO}_{2}$, involving especially the influence of surface $\mathrm{ZnOH}$ species originating from water activation, will be discussed.

As highlighted in recent theoretical work $[11,16]$, the presence of the - with respect to clean Pd - electronically- altered PdZn surface is certainly crucial for steering the individual dehydrogenation steps from methanol to $\mathrm{CO}$. The enhanced stability and thus preferential formation of formaldehyde on the $\mathrm{PdZn}(111)$ surface and the suppression of its dehydrogenation to $\mathrm{CO}$ were already predicted in [16]. However, the mechanistic link between e.g. bimetallic $\mathrm{CH}_{2} \mathrm{O}$ stabilization and the preferential formation of $\mathrm{CO}_{2}$ in MSR is still unclear. The latter obviously requires water activation as a "source of oxygen" at or near the bimetallic surface, in order to add an additional oxygen atom into a dehydrogenated methanol species (e.g. $\mathrm{CH}_{2} \mathrm{O}$ (ads)), to create a $\mathrm{CO}_{2}$-precursor such as formic acid at the surface. Theory examined the likely forms of formaldehyde and water at the PdZn surface, which are then supposed to interact toward $\mathrm{CO}_{2}[11,16,17]$. We may ask the questions where and how water is activated, e.g. at the bimetallic $\mathrm{PdZn}$ surface itself, at local "ionic" Zn sites arising from chemically-induced segregation, or at the phase boundary $\mathrm{PdZn} / \mathrm{ZnO}$, as suggested in [15], and where and how these oxygen-containing species, e.g. $-\mathrm{OH}$ groups, interact with which specific methanol-derived $\mathrm{C}_{1}$-oxygenates to form the optimum $\mathrm{CO}_{2}$ precursor species. For this reason the propensity of $\mathrm{Cu}$ or other metal surfaces [18] and of $\mathrm{ZnO}$ surfaces [19-23] for water dissociation, being an important aspect for all reforming reactions, has already been studied extensively. However, pure $\mathrm{ZnO}$ is unselective with respect to $\mathrm{CO}_{2}$ formation and rather favors $\mathrm{CO}$ production [24].

The ideal, "theory-compatible" case of a bifunctional 1:1 PdZn alloy surface being highly selective, without the need of a phase boundary to the $\mathrm{ZnO}$ support, is opposed by the classical picture of a mechanistic synergism between $\mathrm{PdZn}$ and $\mathrm{ZnO}$. That $\mathrm{ZnO}$ may still be important to enhance $\mathrm{CO}_{2}$ formation has been clearly demonstrated by Bera and Vohs [15]. These authors found evidence for a lowtemperature reaction channel for the oxidation of methanolderived species to $\mathrm{CO}_{2}$ on $\mathrm{Pd} / \mathrm{ZnO}(0001)$, in which oxygen was supplied by the $\mathrm{Zn}(0001)$ support. The preferential decomposition of methanol toward $\mathrm{CO}$ and hydrogen was observed both on $\mathrm{Pd}$ and $\mathrm{PdZn}$ deposited on $\mathrm{ZnO}(0001)$, when the influence of the oxide-metal phase boundary was suppressed. From this study it appears likely that also water activation and the oxidation processes leading to $\mathrm{CO}_{2}$ involve reactions at the bimetal-oxide phase boundary. On $\mathrm{PdZn}$, in the absence of water, the formation of $\mathrm{CO}$ and $\mathrm{H}_{2}$ both from formaldehyde and methanol [25] is a matter of fact, but Rösch and coworkers rather attributed this process to structural defects present on the 1:1 PdZn system [16].

On the other hand a complementary study is available which highlights the exclusive role of bimetallic PdZn particles prepared on an inert support for highly selective MSR. Suwa et al. showed that PdZn alloy particles supported on carbon-black led to enhanced $\mathrm{CO}_{2}$ selectivity [26]. Again, the unknown oxidation state(s) of the involved Zn surface species occurring under "real" MSR conditions hamper a clear experimental proof for the exclusive $\mathrm{PdZn}$ bimetallic action. Nevertheless, this study provided some bias for the water-activating role of PdZn surface ensembles, or, at least, local ionic $\mathrm{Zn}$ species within a bimetallic 
surface environment, e.g. formed under reaction conditions by partial $\mathrm{Zn}$ segregation.

The model catalyst approach applied in this work not only allows us to differentiate-the catalytic properties of the pure bimetallic systems from those involving an oxidemetal phase boundary, but - most importantly - to identify the $\mathrm{Zn}$ oxidation state(s) and the electronic state of Pd insitu on the working catalyst surface.

\section{Experimental}

The preparation and characterization of the $\mathrm{PdZn}$ model catalysts were performed under ultrahigh vacuum (UHV) and mbar gas pressure, using three different experimental setups. The first setup (for high-pressure kinetic studies) is located at Innsbruck University [27], the second one (for high-pressure in-situ XPS) at the HZB/BESSY II synchrotron facility (Berlin, Germany) [28], and the third one (for in-situ PM-IRAS) at Vienna University of Technology [29]. A detailed description of all three systems is given in the supporting information section of [14].

In order to compare the results in an unambiguous manner, the sample preparation was monitored in all setups by XPS and LEED, and the same Pd foil sample was used for the in-situ XPS and high-pressure catalysis studies, using identical preparation/reaction conditions.

\subsection{Innsbruck experimental setup}

The UHV system with attached high-pressure reaction cell [27] is designed for catalytic studies up to 1 bar on a larger piece of $2 \mathrm{~cm} \times 2 \mathrm{~cm}$ polycrystalline $\mathrm{Pd}$ foil, allowing us to detect reaction products and even minor intermediates with high sensitivity, either by discontinuous sample injection into the gas chromatography-mass spectrometry (GC-MS) setup (HP G1800A) or by direct online MS analysis of the reaction mixture via a capillary leak into the GC/MS detector. The system consists of an UHV chamber with a long-travel Z-manipulator and a small-volume Pyrex glass reactor ( $52 \mathrm{ml}$, no hot metal components) attached to the outside of the UHV chamber and accessible via a sample transfer port. The UHV chamber is equipped with an XPS/Auger/ISS spectrometer (Thermo Electron Alpha 110) and a standard double $\mathrm{Mg} / \mathrm{Al}$ anode X-ray gun (XR 50, SPECS), an Omicron ISE 100 ion gun to provide the focused $1 \mathrm{keV} \mathrm{He}^{+}$ions for ISS, an electron beam heater, an ion sputter gun and a mass spectrometer (Balzers). All ISS experiments were performed at an angle of beam incidence $\Psi=45^{\circ}$ and a scattering angle of $\vartheta=90^{\circ}$, and after correction for the different cross-sections, intensity normalization of the $\mathrm{Pd}$ and $\mathrm{Zn}$ signals was performed relative to the total backscattering yield, i.e. $\mathrm{I}_{\mathrm{Zn}}$ (normalized $)=\mathrm{I}_{\mathrm{Zn}} /\left(\mathrm{I}_{\mathrm{Pd}}\right.$ $\left.+\mathrm{I}_{\mathrm{Zn}}\right)$ and $\mathrm{I}_{\mathrm{Pd}}$ (normalized) $=\mathrm{I}_{\mathrm{Pd}} /\left(\mathrm{I}_{\mathrm{Pd}}+\mathrm{I}_{\mathrm{Zn}}\right)$. The $\mathrm{Pd}$ and $\mathrm{Zn}$ scattering cross-sections valid for our specific setup were determined by measurement of the clean Pd foil and a suf- ficiently thick pure $\mathrm{Zn}$ metal surface layer covering all $\mathrm{Pd}$ under identical experimental conditions. For controlled $\mathrm{Zn}$ deposition, a home-built $\mathrm{Zn}$ evaporator was attached, which consists of a resistively-heated glass effusive cell filled with $\mathrm{Zn}$ shot (99.99\%) and a water-cooled quartz-crystal microbalance to control the amount of deposited $\mathrm{Zn}$. Samples are transferred by means of a magnetically coupled transfer rod at first to the UHV sample holder and finally to a Pyrex glass sample holder used inside the reaction cell. With this all-glass setup no wires or thermocouples are connected to the sample during catalytic measurement and, therefore, background (blind) activity of the reaction cell is negligible. The main chamber is pumped by a turbomolecular pump, an ion getter pump and a titanium sublimation pump to a base pressure in the low $10^{-10}$ mbar range. High purity gases $\left(5.0 \mathrm{H}_{2}, \mathrm{O}_{2}\right.$, Ar) were used as supplied from Messer-Griesheim and dosed via UHV leak valves. The high-pressure cell is evacuated sequentially by a rotary pump (via $\mathrm{LN}_{2}$ cooled zeolite trap) and then via the main chamber down to UHV base pressure, and can be heated from outside to $723 \mathrm{~K}$ with an oven covering the cell. For better mixing of the reactants, the high-pressure cell is operated in circulating batch mode. By using an uncoated GC capillary attached to the high-pressure cell, the reaction mixture in the close vicinity of the sample is analyzed continuously by the mass spectrometer of the GC/MS system. MS signals of methanol, $\mathrm{CO}_{2}, \mathrm{CO}, \mathrm{H}_{2}$ and $\mathrm{CH}_{2} \mathrm{O}$ were externally calibrated and corrected for fragmentation (that is, $\mathrm{CO}$ and $\mathrm{CH}_{2} \mathrm{O}$ fragments for methanol, $\mathrm{CO}$ fragment for $\mathrm{CO}_{2}$ ).

A polycrystalline palladium foil (Goodfellow, purity $99.999 \%, 0.125 \mathrm{~mm}$ thick, size $3.5 \mathrm{~cm}^{2}$ ) was cleaned on both sides by successive cycles of $\mathrm{Ar}^{+}$ion bombardment (6.0x $10^{-5}$ mbar Ar, $503 \mathrm{eV}, 1 \mu \mathrm{A}$ sample current), oxidation $\left(5.0 \times 10^{-7} \mathrm{mbar}_{2}, \mathrm{~T}=1000 \mathrm{~K}\right)$, and annealing in hydrogen $\left(5.0 \times 10^{-7} \mathrm{mbar}_{2}, \mathrm{~T}=700 \mathrm{~K}\right)$ and in vacuum $(\mathrm{T}=1000 \mathrm{~K})$ until no impurities were detected by AES and XPS. Details of the preparation of the PdZn multilayer alloy will be given in section 3.1. Methanol and methanol/water mixtures were degassed by repeated freeze-and-thaw cycles. All MSR reactions were conducted with methanol/water mixtures of a 1:10 composition of the liquid phase. This corresponds to a room temperature partial pressure ratio of methanol:water in the equilibrium gas phase of 1:2.

The catalytic experiments were performed in a temperature-programmed manner, i.e. the reaction cell was heated at a constant linear rate of $\sim 8 \mathrm{~K} / \mathrm{min}$ to the final temperature of $623 \mathrm{~K}$, and then kept isothermally at this temperature for $\sim 20 \mathrm{~min}$. Experimental details will be given in context with the individual reaction runs, see sections 3.4 and 3.5. The advantage of the TPR (temperature programmed reaction) runs is that pronounced selectivity changes can be monitored via the partial pressure changes as a function of the reaction temperature, yielding useful qualitative information about changes of the reaction mechanism and the catalyst state.

The main strength of the all-glass high-pressure cell, as described in detail in [27], is that any heated metal parts 
coming into contact with the respective reaction gas mixture are avoided, which is of paramount importance when measuring reaction rates on the model catalyst surfaces which exhibit only a small surface area of a few $\mathrm{cm}^{2}$. Therefore, also blind reaction runs under the exactly identical reaction conditions are regularly performed to ensure the "intrinsic inactivity" of our setup. The reactor volume, including recirculation pump and gas lines, is fixed, and the initial reactant mixture is first premixed and then admitted to the reactor using high precision piezoresistive pressure gauges, which allow for a very accurate determination of both the ratio and the total amount of reactant molecules initially supplied to the reactor - thus exact control of the "starting amount" of reactants is possible. Then the reaction mixture is completed to 1 bar by a He-Ar mixture of defined composition. The reaction can be started at room temperature (as it was the case for the present work, in order to monitor temperature-dependent selectivity effects) using a linear ramp generator to increase the reactor temperature up to the final isothermal section, or alternatively be started isothermally already at the final reaction temperature (gas admission after T-ramp). In any case, the partial pressure changes vs. time are monitored using the MSD of our HP GCMS system directly via a capillary leak, which will withdraw less then $1 \%$ of the total reaction mixture during $\sim 1$ h of reaction, so this change can be basically neglected. In the same turn, the reactor is heated to approach the final temperature, which increases the total pressure in the system by $\sim 20 \%$. To compensate for the total resulting pressure effect, we always use a fixed partial pressure of Argon added to the initial reaction mixture and use the Ar MSD signal change to renormalize all pressure changes back to the basis of the initial conditions.

In our MSR- and methanol dehydrogenation experiments on active $\mathrm{PdZn}$ surfaces typically $\sim 50 \%$ of the initially admitted methanol are reacted off within 30 minutes, depending on the catalyst's activity. The (already pressure-change corrected) product mass traces increase from a base level (corresponding to no product in the beginning) to a final value. The precision of the whole rate-determination procedure now depends on how precisely the final reactant pressures can be determined. We use an internal standard method, i.e. the addition of a well-defined molar amount of the respective product will create a step in the MSD trace which then can be used to determine the individual product amounts at a given time $t$ with high accuracy. Now we can normalize the MSD traces to (corrected) pressure change, whereby the limiting (pre/post) values are exactly known. On the basis of the precisely known reactor volume we can now recalculate how many molecules of reactants were consumed/ how many product molecules were formed as a function of time. The first derivative of these curves will yield molecules consumed/formed per second.

To determine TOF values some additional assumptions with respect to the number of active sites must be made. Since the geometric surface area of our foil sample is precisely known, we usually assume a 1:1 mixture of (111) and (100) oriented facets and thus the average Pd atom density of our foil is assumed at $1.4 \times 10^{15}$ atoms $/ \mathrm{cm}^{2}$, just half way between the values for the respective single crystals. On the 1:1 PdZn surface alloys, we may additionally assume $50 \%$ of this number.

\subsection{HZB/BESSY II experimental setup}

The HZB/BESSY II system [28] (at beamlines U49/2-PGM1 and later at ISISS) allowed us to perform insitu photoelectron spectroscopy up to 1 mbar total reactant pressures. The data obtained at these - with respect to the HP cell described in 2.1.- relatively low pressures complement the kinetic experiments performed in Innsbruck, which were in part also performed in the sub-mbar pressure range, in order to study a possible pressure gap effect between the Innsbruck and the HZB measurements. The sensitivity of the simultaneous MS detection of the reaction products at HZB/BESSY II was not sufficient to extract reliable reaction rate and selectivity data for $\mathrm{CH}_{2} \mathrm{O} / \mathrm{CO}_{2}$, mainly because of an unfavorable ratio of the large total reactant flow through the XPS high pressure cell (which is generally operated in constant flow mode) relative to the minor amounts of $\mathrm{CO}_{2}$ and $\mathrm{CH}_{2} \mathrm{O}$ formed on the low surface area catalyst (only $\sim 0.5 \mathrm{~cm}^{2} \mathrm{PdZn}$ alloy on Pd foil or $\operatorname{Pd}(111))$. However, experiments using the same reaction conditions with respect to initial reactant pressures, PdZn preparation setup and reaction temperature range, provided a reliable "connection" between the data obtained in either experimental setup.

The HZB/BESSY II setup is equipped with differentially-pumped electrostatic lenses and a SPECS hemispherical analyzer. The sample is positioned inside the highpressure/analysis chamber $\sim 2 \mathrm{~mm}$ away from a $1 \mathrm{~mm}$ aperture, which is the entrance to the lens system separating gas molecules from photoelectrons. Binding energies (BE) were generally referred to the Fermi-edge recorded after each core level measurement. Samples were mounted on a transferable sapphire holder. The temperature was measured by a $\mathrm{K}$-type $\mathrm{Ni} / \mathrm{NiCr}$ thermocouple spot-welded to the side of the sample and temperature-programmed heating was done by an IR laser from the rear. Sample cleaning procedures consisted of repeated cycles of $\mathrm{Ar}^{+}$sputtering at room and elevated temperatures, annealing up to $950 \mathrm{~K}$ in $\mathrm{UHV}$, and exposure to $\mathrm{O}_{2}$, followed by flashing at $950 \mathrm{~K}$ for $60 \mathrm{~s}$ in UHV. The sample cleanliness was checked by XPS. Two kinds of samples were used: a smaller piece of the identical Pd foil sample used in Innsbruck and, in addition, a (111)-oriented Pd single crystal.

\subsection{Vienna experimental setup}

Polarization-modulation infrared reflection absorption spectroscopy (PM-IRAS) provides surface vibrational spectra of adsorbed species and can be applied from UHV to ambient pressure, based on the accurate subtraction of 
gas phase contributions $[29,32,33]$. As described by the metal surface selection rule [34], the effective surface intensity of s-polarized infrared light on a metal surface is basically zero and no surface absorption occurs. Thus, IR spectra acquired in s-polarization are identical to IR gas phase spectra. In contrast, IR spectra acquired in ppolarization contain absorption contributions of both surface and gas phase species. Consequently, (p-s) spectra represent the vibrational signature of the surface species. Polarization modulation is performed by a photoelastic modulator (Hinds-PEM-90; $\mathrm{ZnSe}$ ) as described in more detail in $[29,33]$. In order to carry out ambient pressure PM-IRAS spectroscopy on single-crystal based model catalysts, a UHV-compatible high-pressure cell, coupled to a UHV surface preparation/analysis system, has been used [33]. After sample preparation/characterization in UHV, the model catalyst was transferred, with the help of an $\mathrm{xyz} \theta \square$ manipulator and still under UHV, to the spectroscopy/reaction cell, where experiments in the range from UHV to 1 bar can be performed (such as PM-IRAS using a BRUKER IFS66v/S spectrometer). The preparation of $\operatorname{Pd}(111)$ and PdZn multilayer near surface alloys was performed in analogy to the Innsbruck and HZB/BESSY experiments and confirmed by LEED and XPS. For PMIRAS, CO (purity >99.997\%) was passed over a carbonyl absorber cartridge and then introduced via a cold trap filled with liquid nitrogen in order to remove potential $\mathrm{Ni}$ - and Fe-carbonyl impurities.

\section{Results and discussion}

\subsection{The PdZn "multilayer" alloy preparation veri- fied by AES and LEIS}

Prior to catalytic measurements, the preparation of a suitable "multilayer" PdZn alloy both on the surface of Pd foil and $\operatorname{Pd}(111)$ was examined, building upon knowledge obtained by previous structural investigations of $\mathrm{Zn}$ deposition and alloy formation on $\operatorname{Pd}(111)$, by Bayer et al. [5], Gabasch et al. [6], Weirum et al. [34], Kratzer et al. [35] and Stadlmayr et al. [12,36]. To avoid sticking coefficients of $\mathrm{Zn}$ smaller than 1 on the quartz microbalance, which would lead to underestimation of $\mathrm{Zn}$ thickness as reported in [35], the microbalance was cleaned by $\mathrm{Ar}^{+}$sputtering and cooled to below $270 \mathrm{~K}$ during evaporation.

To calibrate the amount of $\mathrm{Zn}$ required for one monolayer, $\mathrm{Zn}$ was deposited on the clean Pd foil at $\sim 300 \mathrm{~K}$ sample temperature at an evaporation rate of $12 \mathrm{~Hz} / \mathrm{min}$. Zn was successively deposited in $3 \mathrm{~Hz}$ intervals and Auger spectra of the $\mathrm{Zn}-\mathrm{L}_{3} \mathrm{M}_{45} \mathrm{M}_{45}$ (1G) (kinetic energy $992 \mathrm{eV}$ ) and the Pd-M $\mathrm{M}_{5} \mathrm{~N}_{45} \mathrm{~N}_{45}(1 \mathrm{G})$ (commonly MVV) peaks (kinetic energy $327.8 \mathrm{eV}$ ) were recorded after each evaporation/deposition step. After differentiation, the peak-to-peak height of the $\mathrm{Zn}$ signal was plotted versus the $\mathrm{Zn}$ exposure (Fig. 1). In a further experiment, an analogous calibration procedure was performed, but modified by an additional
$503 \mathrm{~K}$ thermal annealing step after each deposition. After each step, Auger spectra were again collected, and the results are depicted in Fig. 1.

In order to interpret the data of Fig.1, additional information about the growth mode and morphology of $\mathrm{Zn}$ on $\mathrm{Pd}$, both at $\sim 300 \mathrm{~K}$ and $503 \mathrm{~K}$, is required. Some - partly controversial - information is reported in the literature. For $\mathrm{Zn}$ deposited at 105-150 K simultaneous multilayer (Frank-van-der-Merwe) growth of $\mathrm{Zn}$ on-top of $\mathrm{Pd}$, as reported in $[5,36]$, can be safely assumed both on $\operatorname{Pd}(111)$ and polycrystalline Pd. At $\sim 300 \mathrm{~K}$ the degree of PdZn alloy formation is still a matter of debate. According to Stadlmayr et al. [36], alloying on $\operatorname{Pd}(111)$ starts just above 300 $\mathrm{K}$, in good agreement with an XPS study by Bayer et al. [5], who also observed the very onset of the transformation from the Pd-Zn(ads) interface to the PdZn alloy state around $300 \mathrm{~K}$. A recent STM study by Weirum et al. [34] reported spontaneous formation of PdZn bilayer alloy islands at $\sim 300 \mathrm{~K}$, as concluded from the local occurrence of ordered $\mathrm{p}(2 \mathrm{x} 1)$ patches and the height of the islands. Considering the combined information, it appears rather unlikely that temperatures below $300 \mathrm{~K}$ are sufficient to induce complete alloying of $1 \mathrm{ML}$ of $\mathrm{Zn}$ toward a full "bilayer alloy" situation on $\operatorname{Pd}(111)$. Concluding, only a minor degree of alloying might appear on the $\operatorname{Pd}(111)$ surface e.g. at $293 \mathrm{~K}$.

In contrast, $\mathrm{Zn}$ deposition at temperatures around $300 \mathrm{~K}$ on the Pd foil sample - exhibiting a more structural defects (steps, grain boundaries) than well-annealed $\operatorname{Pd}(111)$ - induces a much higher degree of alloying. In the Pd3d spectra taken directly after deposition (but before heating) the presence of a pronounced $\mathrm{Pd} 3 \mathrm{~d}$ component at $\sim 336.3 \mathrm{eV}$ provided clear evidence.

From this viewpoint we interpret the $\sim 300 \mathrm{~K}$ AES calibration data in Fig.1 by assuming sequential deposition of $\mathrm{Zn}$ monolayers partly in the alloy state and partly on-top of the (already) alloyed Pd foil surface: the first $\mathrm{Zn}$ ML is completed at $\sim 24 \mathrm{~Hz}$, likely yielding the PdZn "bilayer" structure suggested by Weirum et al. [34], and the second $\mathrm{ML}$ of $\mathrm{Zn}$ is completed at $\sim 48 \mathrm{~Hz}$, corresponding to a pure $\mathrm{Zn}$ adlayer on-top of the more or less complete PdZn bilayer structure. Finally, "Zn on Zn" layers are deposited above $48 \mathrm{~Hz}$. This sequence is supported by the obvious changes of the slope, which can be explained by superimposing the relative AES intensity contributions of the first, second, third, and all additional alloy/metal layers.

After completion of the first two alloy layers (the full bilayer alloy) at $1 \mathrm{ML}$ of $\mathrm{Zn}$, the (inter)layer below is still clean $\mathrm{Pd}$ and does therefore not contribute to the $\mathrm{Zn}$ intensity; after the second ML of Zn both the PdZn bilayer and the $\mathrm{Zn}$ adlayer on-top of it contribute, but not the then fourth (inter)layer of $\mathrm{Pd}$, and so on. Essentially, the $\mathrm{Zn}$ intensity should level off at the value of pure $\mathrm{Zn}$, once enough layers were deposited to fully screen the Pd substrate.

In order to cross-check our coverage assignment independently, the convergence of the Pd and Zn AES signals at $\sim 300 \mathrm{~K}$ with increasing $\mathrm{Zn}$ exposure was modeled by a 
simple calculation of the exponential intensity attenuation with probe depth.

$$
I_{P d}=I_{0, P d}\left(\exp ^{-t\left(\frac{1}{L_{328 e V}^{\text {auger }}}\right)}\right)
$$

The maximum attainable $\mathrm{Zn}$-LMM signal at a given $\mathrm{Zn}$ (multi-)layer thickness can be calculated by:

$$
I_{Z n}=I_{0, Z n}\left(1-\exp ^{-t\left(\frac{1}{L_{992 e V}^{\text {auger }}}\right)}\right)
$$

Here $t$ is the thickness of the overlayer in $\AA$; $L^{\text {auger }}$ are the electron attenuation lengths (or Inelastic Mean Free Path (IMFP)), which are a function of kinetic energies of the Auger electrons; $I_{0}$ are the intensities of the respective signals at $t \rightarrow \infty$.

From Fig. 1 we derive that the MVV signal of Pd at 114 $\mathrm{Hz}$ is attenuated to $\sim 18 \%$ of the value of pure Pd (ratio $\mathrm{I}_{\mathrm{Pd}} / \mathrm{I}_{0}$ of $\sim 0.18$ )

Vice versa, based on comparison with $\mathrm{Zn}$ layers sufficiently thick to fully screen the Pd underneath, we derived that the $\mathrm{Zn}-\mathrm{LMM}$ intensity at $114 \mathrm{~Hz}$ corresponds to $\sim 60 \%$ of the maximum attainable intensity (i.e of pure $\mathrm{Zn}$ metal), i.e at $114 \mathrm{~Hz}$ we found $\mathrm{I}_{\mathrm{Zn}} / \mathrm{I}_{0} \sim 0.6$. $L_{992 e \mathrm{~V}}$ in Zinc is $\sim 12 \AA$, and $L_{328 \mathrm{eV}} \sim 5 \AA$. Thus, $t$ at $114 \mathrm{~Hz}$ can be calculated both from the $\mathrm{Pd}$ and $\mathrm{Zn}$ signal attenuation by the $\mathrm{Zn}$ overlayers:

$t=\ln \left(\frac{I_{P d}}{I_{0}}\right)\left(-L_{328 e V}^{\text {auger }}\right)=8.6 \AA$

and alternatively:

$t=\ln \left(1-\frac{I_{Z n}}{I_{0}}\right)\left(-L_{992 e V}^{\text {auger }}\right)=12.8 \AA$

The discrepancy between the two numbers can be explained if one accounts for the partial bilayer alloy formation above $300 \mathrm{~K}$. Partial alloying will cause incorporation of $\mathrm{Pd}$ atoms in layers closer to the top layer, causing less Pd-MVV attenuation than for a simple on-top layer-bylayer growth scenario without alloying. Vice versa, additional $\mathrm{Zn}$ layers will be required to obtain saturation of the $\mathrm{Zn}$ signal at the value of pure $\mathrm{Zn}$, as compared to the simple on-top deposition case.

The $\mathrm{Zn}$ inter-atomic distance in clean $\mathrm{Zn}$ metal is 2.7 $\AA$, i.e. using this calculation we estimate the $\mathrm{Zn}$ layer thickness at $114 \mathrm{~Hz}$ to amount to $\sim 4.0 \mathrm{ML}$ of $\mathrm{Zn}$, as com

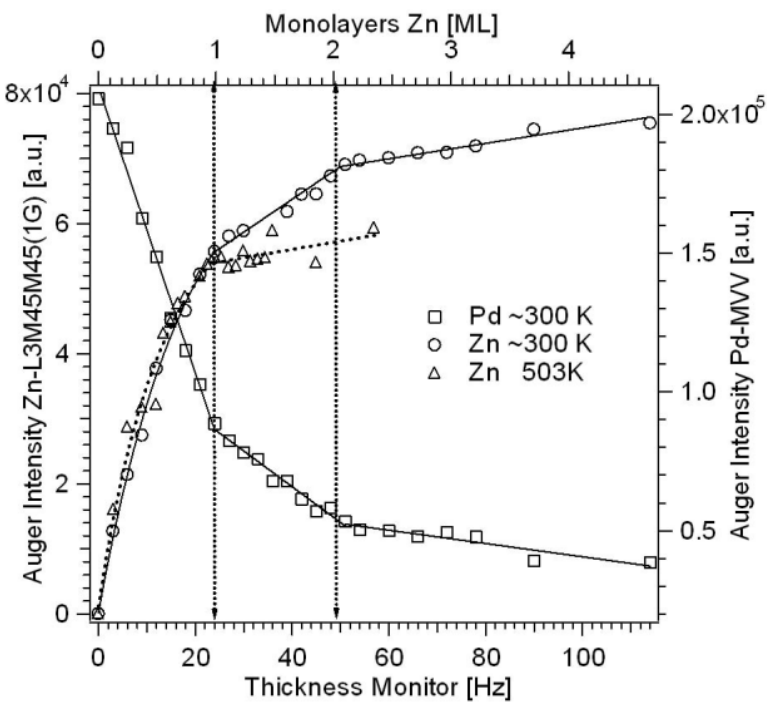

Fig. 1: Peak-to-peak intensities of the differentiated $\mathrm{Zn}-\mathrm{L}_{3} \mathrm{M}_{45} \mathrm{M}_{45}$ (1G) Auger peak and the Pd- $\mathrm{M}_{5} \mathrm{~N}_{45} \mathrm{~N}_{45}$ (1G) peak (usually denoted as MVV) as a function of the $\mathrm{Zn}$ deposition at $300 \mathrm{~K}$ and after annealing at $503 \mathrm{~K}$.

pared to the 4.8 ML derived from Fig.1, reasonably confirming our calibration in Fig.1

In any case, according to [5,34,36], when $>3 \mathrm{ML} Z \mathrm{Zn}$ deposited on-top of $\mathrm{Pd}(111)$ are annealed to $503 \mathrm{~K}$, complete $\mathrm{Zn}$ alloying with $\mathrm{Pd}$ is obtained. In ref. [5], the maximum alloy-induced binding energy (BE) of the $\mathrm{Pd} 3 \mathrm{~d}$ component was $\sim 336.1 \mathrm{eV}$ and was reached upon annealing at $\sim 500 \mathrm{~K}$. This can be interpreted in terms of a $\mathrm{Zn}$ coordination number of Pd atoms of up to $6(1: 1$ bulk alloy), which can be regarded as optimum initial state for catalytic experiments, because an optimized (modified) surface electronic structure together with a defined $(1: 1)$ surface composition were already verified [12]. Bayer et al. [5] also distinguished between a "2D-alloy", obtained by annealing one single $\mathrm{ML}$ of $\mathrm{Zn}$, and a thicker " $3 \mathrm{D}$ " alloy state, obtained by thermal annealing of a $300 \mathrm{~K} 3 \mathrm{ML} \mathrm{Zn}$ deposit or by directly depositing $3 \mathrm{ML}$ at an elevated sample temperature of $503 \mathrm{~K}$. The latter two procedures then give rise to the typical multilayer PdZn alloy state with a $\mathrm{Pd} 3 \mathrm{~d}$ component around $336.1 \mathrm{eV}$. Using only $1 \mathrm{ML}$ of $\mathrm{Zn}$, the maximum $\mathrm{BE}$ of the $\mathrm{Pd} 3 \mathrm{~d}$ "2D-alloy" component did not exceed $335.6 \mathrm{eV}$ at the optimum annealing temperature around $503-550 \mathrm{~K}$, corresponding to complete formation of a bilayered "2D-alloy" over the whole surface area, provided that a perfect $1: 1 \mathrm{PdZn}$ ratio is present in the first two metal layers after "quantitative" alloying.

On this basis may we assign the pronounced break of the $503 \mathrm{~K}$ calibration curve in Fig. 1, observed at $24 \mathrm{~Hz}=1$ ML (as derived from the $\sim 300 \mathrm{~K}$ curve), to the completion of the " $2 \mathrm{D}$ alloy = bilayer" state. We therefore have to assume that the first two alloy layers contribute most of the $\mathrm{Zn}$ AES intensity, and that formation of additional alloy layers "deeper than two" by the extra Zn coverage $>1$ ML gives rise to the reduced slope of the $503 \mathrm{~K}$ curve beyond 1 ML, due to the discussed attenuation effect. The steep and 


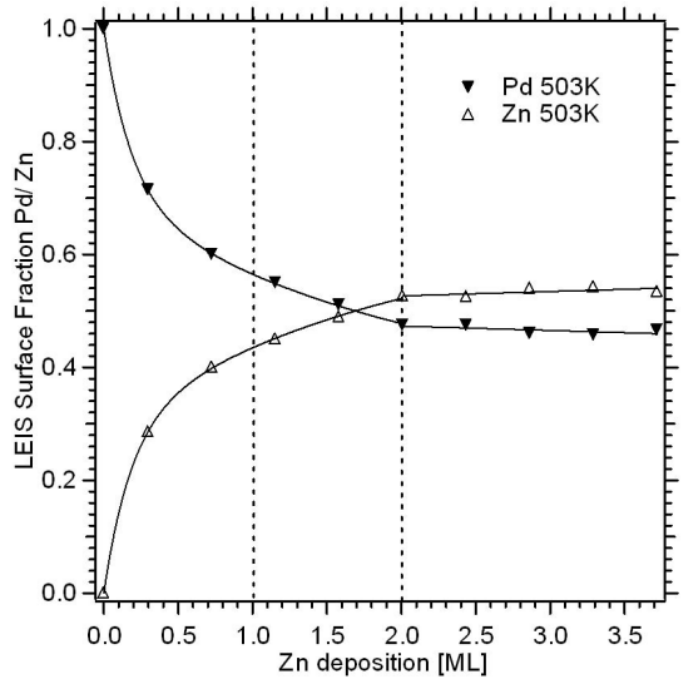

Fig. 2: LEIS-derived Pd:Zn surface composition on Pd foil after $\sim 300 \mathrm{~K}$ Zn deposition and subsequent thermal annealing at $503 \mathrm{~K}$

close-to-linear increase of the Zn AES $503 \mathrm{~K}$ intensity between 0 and $22 \mathrm{~Hz}$ can be interpreted in terms of an increase of the relative bilayer alloy island surface area between 0 and $100 \%$ between 0 and 1 ML Zn coverage, in accordance with the growth model proposed by Weirum et al [34].

In order to determine the catalytically most relevant top layer composition of the PdZn alloy model catalyst as a function of $\mathrm{Zn}$ amount and annealing temperature, additional $\sim 300 \mathrm{~K} \mathrm{Zn-deposition}+300-800 \mathrm{~K}$ annealing experiments were examined by LEIS . As can be seen in Fig.2, the LEIS intensities of $\mathrm{Pd}$ and $\mathrm{Zn}$ approach the expected $\sim 1: 1$ ratio already at a $\mathrm{Zn}$ deposition of $1 \mathrm{ML}$, followed by annealing at $503 \mathrm{~K}(42: 58=\mathrm{Zn}: \mathrm{Pd})$. Beyond $1 \mathrm{ML}$, up to 2 $\mathrm{ML}$, the ratio gradually changed to 53:47 in favour of $\mathrm{Zn}$ (which can be assigned to an effective 1:1 ratio within the error limit of our measurements), and above $2 \mathrm{ML}$ this ratio remained almost constant with further $\mathrm{Zn}$ exposure.

According to Weirum et al. [34], thermal annealing of $>1$ ML Zn offers two different pathways for Zn: desorption back to the gas phase or alloying to form a thicker alloy which exceeds the "bilayer $=2 \mathrm{D}$ " state. Apparently, the relative rates of desorption and alloying depend both on the total amount of extra $\mathrm{Zn}>1 \mathrm{ML}$ and on the time available for alloying without fast simultaneous desorption. The TPD series presented in [34] suggests that at $503 \mathrm{~K}$ the $\beta_{1^{-}}$ state, assigned to the first pure $\mathrm{Zn}$ ML deposited on-top of the already completed "bilayer=2D" PdZn alloy state, desorbed only at a low rate (peak maximum at $\sim 530 \mathrm{~K}$ ), whereas all further $\mathrm{Zn}$ layers (i.e. Zn on-top of $\mathrm{Zn}$ ) desorbed quickly well below $503 \mathrm{~K}$. Consequently, upon holding the sample isothermally at $503 \mathrm{~K}$, in total $\geq 2 \mathrm{ML}$ of $\mathrm{Zn}$ should contribute to the final alloy layer, meaning that the multilayer alloy state should consist of four or more layers of (1:1) PdZn alloy. Also, the differences of the PdZn Pd3d "2D alloy" and "multilayer" alloy components (335.6 vs. $336.1 \mathrm{eV}$, respectively), observed by Bayer et al. after an- nealing $1 \mathrm{ML}$ and $3 \mathrm{ML} \mathrm{Zn}$ at $503 \mathrm{~K}$ [5], should be interpreted on this basis, suggesting for the multilayer state an increased coordination number of $\mathrm{Pd}$ by $\mathrm{Zn}$ residing in deeper alloy layers.

On this basis, the region between 1 and 2 ML Zn exposure in Fig. 2 is interpreted in terms of the transition from the "2D-alloy" to the "multilayer" alloy state, by consumption of the second ML of $\mathrm{Zn}$ to form a multilayered surface alloy consisting of $\sim 4$ layers of PdZn. It appears possible that this is accompanied by a further increase of the $\mathrm{Zn}: \mathrm{Pd}$ surface ratio toward the eventually expected stable (1:1) composition of the PdZn bulk alloy state. Another explanation comes from a recent LEIS study by Stadlmayr et al. on $\mathrm{Zn} / \mathrm{Pd}(111)$, revealing a $\mathrm{Zn}$ "outward" relaxation observed for the multilayer alloy case, thus improving the "visibility" of $\mathrm{Zn}$ for ion scattering [12].

The standard preparation procedure, finally chosen for the PdZn model catalyst (both on Pd(111) and Pd foil, and irrespective which UHV system was used) thus involved deposition of $3 \mathrm{ML} \mathrm{Zn}$ at $\sim 300 \mathrm{~K}$ (in order to exceed the $2 \mathrm{ML}$ "multilayer alloy" limit), followed by thermal annealing at $503 \mathrm{~K}$ for 5 minutes. This procedure yields the multilayer PdZn alloy state first described by Bayer et al [5] and characterized in more detail by Stadlmayr et al. with respect to its specific surface corrugation by LEIS [12, 14] and with respect to the homogeneous distribution of catalytically active sites by PM-IRAS $[12,14]$.

\subsection{Thermal stability of the PdZn surface alloy on Pd foil determined by AES and LEIS}

The temperature dependent surface composition and, most importantly, the thermal stability of the $3 \mathrm{ML} \mathrm{PdZn}$ multilayer alloy state both on $P d$ foil and $\mathrm{Pd}(111)$ in vacuum between $\sim 300 \mathrm{~K}$ and $800 \mathrm{~K}$ has already been discussed in ref. [12,14], revealing a defined stability region of the multilayer alloy between 500 and $570 \mathrm{~K}$.

In this region also a well-ordered $\mathrm{p}(2 \mathrm{x} 1)$ LEED pattern has been observed on $\operatorname{Pd}(111)$ by various authors [5,6,34,36], and a 1:1 PdZn composition in the surface and subsurface layers has been verified by LEIS $[12,14]$. Hence we conclude that in this temperature region the "Pd foil equivalent" of the well-ordered multilayer $1: 1$ terminated $\mathrm{PdZn}$ alloy is present, as also strongly corroborated by the LEIS data of Fig.2. In full analogy to Pd(111), diffusion of subsurface $\mathrm{Zn}$ into the deeper Pd bulk sets in above $\sim 573$ $\mathrm{K}$, as evidenced by the strong decrease of the AES intensity above $573 \mathrm{~K}$. Note that this decrease in AES is associated with only a small change in the LEIS-detected 1:1 PdZn surface composition.

The annealing temperature of $503 \mathrm{~K}$, chosen for the " $\mathrm{Zn}$ on Pd foil" model catalyst preparation, is therefore located just in the center of the plateau region. It is highly relevant for the catalytic properties of the surface alloy discussed below, that the surface composition did not 
change abruptly above $573 \mathrm{~K}$ (i.e. only from $\mathrm{Zn}: \mathrm{Pd}=52: 48$ to $48: 52$ between 573 and $640 \mathrm{~K}$ ), whereas the $\mathrm{Zn}$ Auger intensity decreased much faster. Obviously, the top layer of 1:1 PdZn exhibits a higher thermal stability than the alloy layers below, resulting in a diffusional loss of the multilayer alloy $\mathrm{Zn}$ to deeper layers before the top layer changes considerably. The transition to the "monolayer" alloy state above $573 \mathrm{~K}$ can be explained by a bulk-diffusion induced lowering of the $\mathrm{Zn}$ coordination of the topmost alloy layer, thus reducing the overall number of $\mathrm{Zn}$ neighbors adjacent to the Pd atoms in the surface layer.

Some of the consequences for XPS spectroscopy of this process on $\mathrm{Pd}(111)$, for the $\mathrm{Pd} 3 \mathrm{~d}$ and $\mathrm{Zn} 2 \mathrm{p}$ core levels, were already described in [5]. In [12], XPS using tunable photon energies at HZB was used to study the related changes in the VB region in greater detail, in particular because changes of the VB electronic structure, especially of the DOS (density of states) near the Fermi edge, are of paramount importance for the catalytic performance $[11,14]$.

Therefore, we also measured the corresponding series of $\mathrm{Pd} 3 \mathrm{~d}, \mathrm{Zn} 3 \mathrm{~d}$ and valence band XPS spectra for thermal annealing of $3 \mathrm{ML} \mathrm{Zn}$ on Pd foil at HZB/BESSY II, which closely resembled the one obtained on $\operatorname{Pd}(111)$ [12] after the respective equivalent treatment (thus not shown here). We explicitly state that the observed thermal changes of the PdZn coordination chemistry are virtually the same on $\operatorname{Pd}(111)$ and $\mathrm{Pd}$ foil.

The valence band region shown in [12], thus also valid for the Pd foil model system, is particularly interesting in view of the aforementioned "pseudo-copper" hypothesis for selective MSR [11,12], suggesting a phenomenological link between the high selectivities of $\mathrm{Cu}$ and $\mathrm{PdZn}$ catalysts resulting from their similar electronic structure. The trend observed in the VB region (BE of 0 to $\sim 6 \mathrm{eV}$ ) is in good qualitative agreement with this idea. For clean Pd and the highly Zn-lean $780 \mathrm{~K}$ alloy state the maximum of the Pd $4 \mathrm{~d}$ related intensity is below $1 \mathrm{eV}$, corresponding to a high DOS close to the Fermi edge. The higher the $\mathrm{Zn}$ coordina- tion of the Pd near-surface layers becomes (with decreasing annealing temperature), the more this intensity maximum shifts towards higher BE. For clean copper we expected a position of the 3d-related intensity maximum at $\sim 2.3 \mathrm{eV}$, confirmed by $\mathrm{Cu}$ spectra obtained at $650 \mathrm{eV}$ photon energy in the same apparatus. The high BE shift of the Pd4d maximum for our "optimum" PdZn alloy obtained by annealing $3 \mathrm{ML} \mathrm{Zn}$ at $503 \mathrm{~K}$ is very close to this value, and does not change upon annealing to e.g. $540 \mathrm{~K}$, i.e. within the stability plateau of the multilayer PdZn alloy state. From this viewpoint, we may anticipate that this state is in fact the most "Cu-like" which can be prepared.

Whereas the rationale in [12] was to study purely the thermal stability of the multilayer PdZn alloy on $\operatorname{Pd}(111)$ under UHV conditions (i.e. in the absence of reactive gases), here we focus on the thermochemical stability under realistic catalytic high pressure conditions.

\subsection{PdZn multilayer surface alloy: thermochem- ical stability under high pressure conditions}

In order to assess the - for the "real" catalytic world more relevant - thermochemical stability of the multilayer PdZn surface alloy state, we performed thermal annealing experiments exposing the multilayer alloy to elevated pressures of water (0.24 mbar), methanol (0.12 mbar), as well as $\mathrm{CO}$ (5 mbar).

Fig. 3 shows the Pd 3d, Zn $3 d$ and the VB spectral regions during heating from $473 \mathrm{~K}$ to $573 \mathrm{~K}$ in water $(0.24$ mbar; i.e. the pressure later on used for MSR). The most remarkable observation in the middle panel of Fig. 3 is a high $\mathrm{BE}$ shoulder of the $\mathrm{Zn} 3 \mathrm{~d}$ peak at $\sim 10.5 \mathrm{eV}$, which increased approximately two times throughout the chosen T-range. This component was not observed in vacuum (UHV) annealing experiments (compare with $\mathrm{Zn} 3 \mathrm{~d}$ region

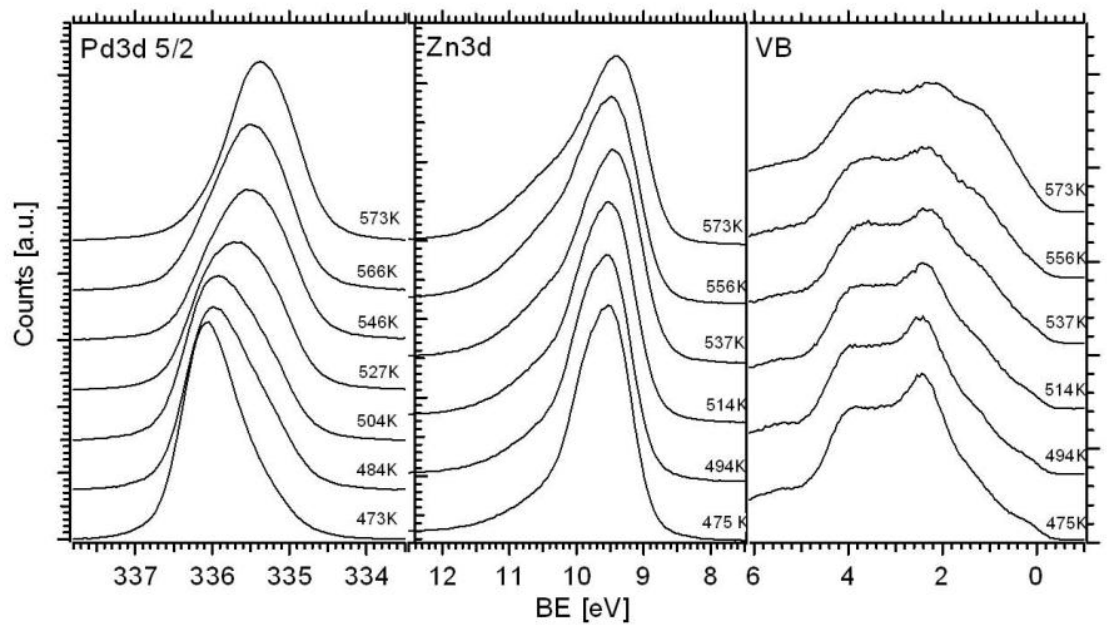

Fig. 3: $\mathrm{Pd} 3 \mathrm{~d}_{5 / 2}, \mathrm{Zn} 3 \mathrm{~d}$ and VB regions measured in-situ during thermal annealing of the $503 \mathrm{~K}$ annealed multilayer PdZn alloy on Pd(111) in 0.24 mbar water pressure between $473 \mathrm{~K}$ and $573 \mathrm{~K}$. Photon energy was $650 \mathrm{eV}$. 


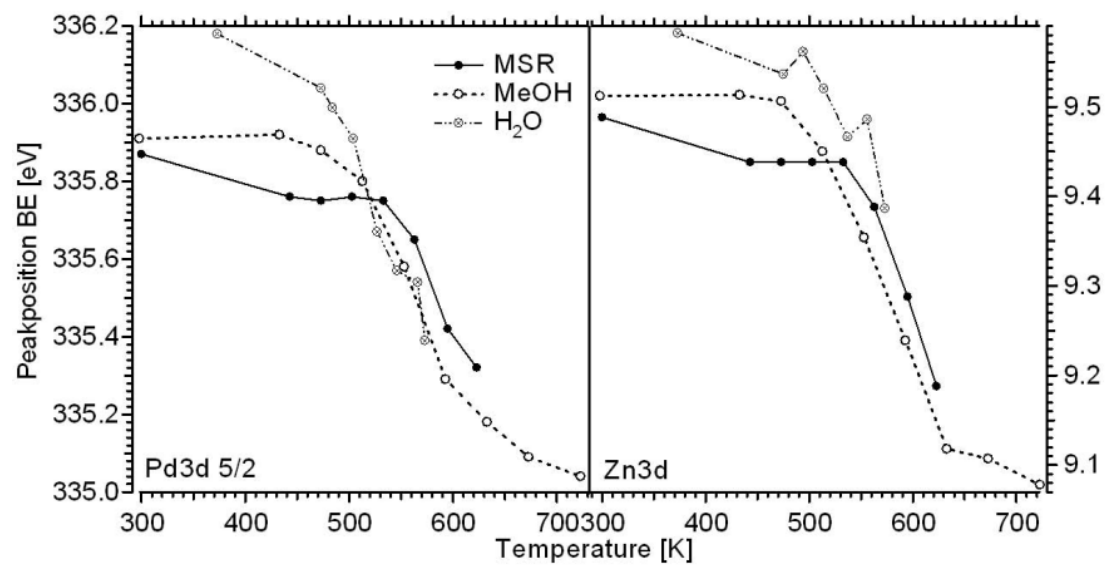

Fig. 4: Temperature-dependent peak position of the $\mathrm{Pd} 3 \mathrm{~d}_{5 / 2}$ and $\mathrm{Zn} 3 \mathrm{~d}$ XPS peaks during annealing in water (black filled circles), methanol (open circles) and a methanol/water steam reforming mixture (1:2, crossed circles).

in Fig. 3 of [12]). XPS depth profiling by varying the photon energy demonstrated the exclusive surface nature of the $10.5 \mathrm{eV}$ species (spectra not shown), being characteristic of an oxidized $\mathrm{Zn}$ species directly at the surface, supposedly $\mathrm{ZnO}(\mathrm{H})$. The Pd 3d signal shifts toward the BE position of metallic Pd upon annealing (left hand panel). In the VB region a strong change in the DOS close to the Fermi edge is observed between $473 \mathrm{~K}$ and $573 \mathrm{~K}$, leading to a much more "Pd-like" electronic structure at $573 \mathrm{~K}$ (see Fig. 3, right panel).

In Fig. 4 the binding energies at the peak maxima of the $P d 3 d_{5 / 2}$ and $\mathrm{Zn} 3 \mathrm{~d}$ core levels are plotted as a function of the annealing temperature, highlighting the stability ranges of the multilayer alloy state in water (crossed circles), in clean methanol vapor (open circles) and in a 1:2 methanol/water steam reforming mixture (filled circles). For the respective vacuum annealing experiment compare ref. [12]. The major spectral changes occur in all gaseous environments above $\sim 550 \mathrm{~K}$ and are largely complete at $630 \mathrm{~K}$. It appears that the chemical environment exerts no pronounced influence on the stability of the multilayer alloy state. Rather, the changes observed under ambient pressure conditions are in good agreement with those observed under UHV conditions [12]. Therein, e.g. the Pd $3 \mathrm{~d}_{5 / 2}$ peak position analogously shifted from $\sim 335.9 \mathrm{eV}$ at $500 \mathrm{~K}$ to $\sim 335.2 \mathrm{eV}$ at $630 \mathrm{~K}$. We conclude that the dominant effect is thermal decomposition of the multilayer alloy by $\mathrm{Zn}$ bulk diffusion. Even in clean water vapor, the alloy decomposition is only to a minor extent a surface oxidation process forming oxidized $\mathrm{ZnO}(\mathrm{H})$ species. The related XPS spectra for methanol (not shown) showed one main difference to the water series of Fig. 3, namely the absence of the $10.5 \mathrm{eV}$ oxidic $\mathrm{ZnO}(\mathrm{H})$ component in methanol, because clean methanol vapor represents a strongly reducing chemical environment.

At this point it becomes clear that the transition from the multilayer alloy state to the subsurface-Zn-lean "monolayer" alloy is by no means a discontinuous process, as already shown in [12]. Changes of the $\mathrm{Zn}$-coordination number of Pd are of gradual nature, which occur to a major extent within $\mathrm{a} \sim 80 \mathrm{~K}$ temperature range (from $\sim 550 \mathrm{~K}$ to $630 \mathrm{~K}$ ), but also continue at higher temperatures.

As CO is a (potential) by-product of MSR and a frequently used probe molecule, we have also examined the thermal stability of the $\mathrm{Zn} / \mathrm{Pd}(111)$ system in a $\mathrm{CO}$ environment using PM-IRAS (Fig. 5). After room temperature $\mathrm{Zn}$ deposition on $\mathrm{Pd}(111)$ in UHV, the sample was annealed $(10 \mathrm{~min})$ to the indicated temperatures in a background pressure of $10^{-6}$ mbar $\mathrm{CO}$ (Fig. 5 a) or 5 mbar $\mathrm{CO}$ (Fig. 5 b). After each annealing step the $\mathrm{Zn} / \mathrm{Pd}(111)$ system was cooled back to $150 \mathrm{~K}\left(10^{-6} \mathrm{mbar}\right)$ or $300 \mathrm{~K}$ (5 mbar), and PM-IRAS spectra were again acquired. This was intended to characterize the resulting PdZn surface structure under conditions close to UHV annealing and close to reactive conditions.

The 1:1 PdZn surface alloy is characterized by a single sharp peak at $\approx 2070 \mathrm{~cm}^{-1}$ (FWHM of $9 \mathrm{~cm}^{-1}$ ), originating from $\mathrm{CO}$ adsorbed on-top of individual $\mathrm{Pd}$ atoms in the Pd rows of the PdZn(111) surface alloy (cf. Fig. 10). This vibrational frequency agrees well with the on-top $\mathrm{CO}$ peak reported for $\mathrm{PdZn}-\mathrm{ZnO}-\mathrm{Al}_{2} \mathrm{O}_{3}$ powder catalysts, after hydrogen reduction/activation of the catalyst [37]. After annealing in $10^{-6}$ mbar CO to $473 \mathrm{~K}$, which in the range of the alloy stability window, the PdZn alloy was clearly established. This proves the homogeneity of the entire multilayer alloy surface, because in case of remaining $\mathrm{Pd}$ patches bridge-bonded CO (at $\approx 1955 \mathrm{~cm}^{-1}$ ) and on-top CO (at $\approx 2085 \mathrm{~cm}^{-1}$ ) would additionally occur at these $\mathrm{p} / \mathrm{T}$ conditions [38-40] (note that the diameter of the IR beam is several $\mathrm{mm})$. Taking into account thermal desorption data $\left(\mathrm{T}_{\mathrm{des}}\right.$ of CO from PdZn is $\sim 210 \mathrm{~K}, \theta_{\text {sat }}=0.5 \mathrm{ML}$ CO) [41], each $\mathrm{Pd}$ atom is occupied by a $\mathrm{CO}$ molecule.

Fig. 5 also shows the effect of higher annealing temperatures, until the PdZn alloy started to decompose at 573 $\mathrm{K}<\mathrm{T}<623 \mathrm{~K}$. The integrated area of the $\sim 2070 \mathrm{~cm}^{-1}$ on-top $\mathrm{CO}$ peak is used as indicator and its temperature depen 

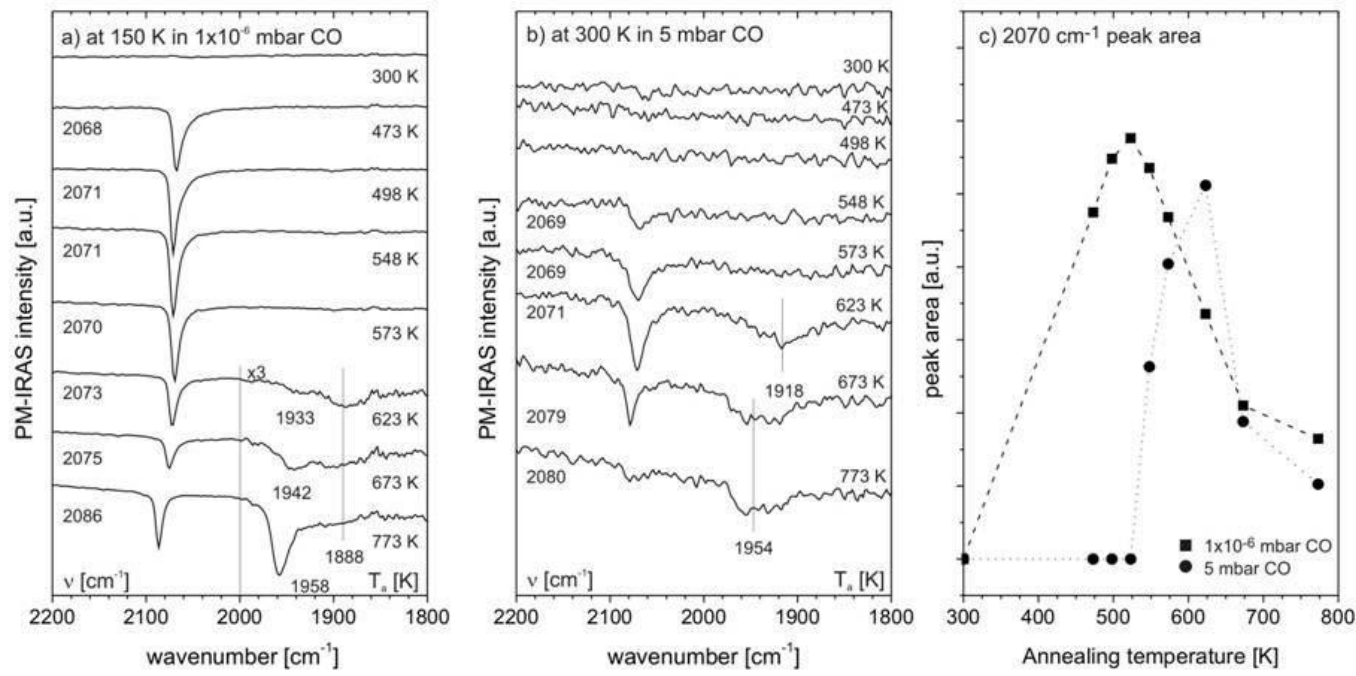

Fig. 5: (a) PM-IRAS spectroscopy of $3 \mathrm{ML} \mathrm{Zn} \mathrm{deposited} \mathrm{at} 300 \mathrm{~K}$ on Pd(111). Spectra were acquired at $150 \mathrm{~K}$ in $10-6 \mathrm{mbar} \mathrm{CO}$ (a), and at $300 \mathrm{~K}$ in 5 mbar CO (b), after successive annealing to the indicated temperatures. The IR intensity in the frequency range of multiple-coordinated $\mathrm{CO}$ (below $2000 \mathrm{~cm}-1$ ) was multiplied by 3 in some spectra. (c) Integrated area of the $\sim 2070 \mathrm{~cm}^{-1}$ on-top CO peak as function of T(anneal).

dence is plotted in Fig. 5 c. In agreement with the LEIS/AES/XPS measurements, there is a stability window up to $\sim 600 \mathrm{~K}$. Interestingly, the intensity of the on-top CO species is highest for the corrugated "Zn-out/Pd-in" surface. Annealing to 623 and $673 \mathrm{~K}$ induced a decrease of the $\sim 2070 \mathrm{~cm}^{-1}$ species, which was successively replaced by $\mathrm{CO}$ resonances characteristic of Zn-lean alloy (broad peak around $1930 \mathrm{~cm}^{-1}$ ) and $\operatorname{Pd}(111)$, the latter with bridge and on-top bonded CO at $\approx 1955 \mathrm{~cm}^{-1}$ and $\approx 2085 \mathrm{~cm}^{-1}$, respectively, and a shoulder at $1890 \mathrm{~cm}^{-1}$ of hollow-bonded $\mathrm{CO}$ [38-40].

Annealing the $\mathrm{Zn}$ deposit in 5 mbar CO led to a remarkable difference in the formation of the PdZn alloy (Fig. 5 b,c). Although one may expect that CO "pulls out" $\mathrm{Pd}$ (due to the larger binding energy of $\mathrm{CO}$ on Pd as compared to $\mathrm{Zn}$ ), it was observed that elevated $\mathrm{CO}$ pressure shifted the onset of alloying to considerably higher temperature. However, once formed, the onset of PdZn decomposition was again found around $600 \mathrm{~K}$ (excluding a simple deviation in temperature measurement as being responsible). The origin of this effect is currently not understood but may be related with the CO-poisoning of surface sites (e.g. steps) that are required for PdZn formation via (partial) diffusion of the $\mathrm{Zn}$ overlayer from the surface to subsurface regions.

\subsection{PdZn multilayer surface alloy: performance in methanol dehydrogenation without water}

The temperature-programmed methanol dehydrogenation run shown in Fig. 6 was performed in the absence of water on a $503 \mathrm{~K}$ annealed multilayer PdZn surface alloy on Pd foil. This experiment yielded a measurable positive rate of $\mathrm{CH}_{2} \mathrm{O}$ formation around $565 \mathrm{~K}$, but no $\mathrm{CO}_{2}$ was

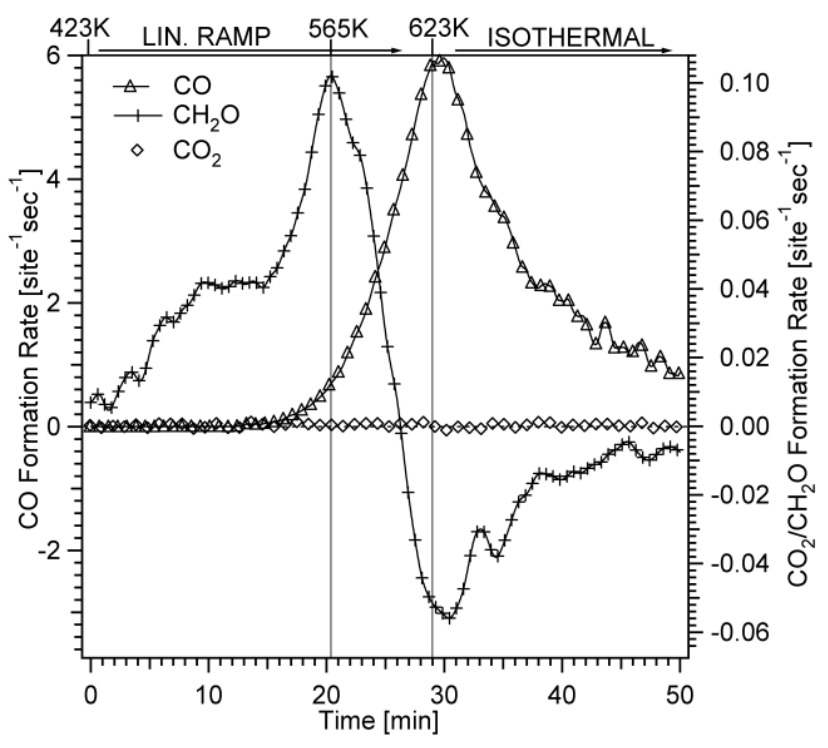

Fig. 6: Temperature-programmed methanol dehydrogenation (initial pressure $60 \mathrm{mbar} \mathrm{MeOH}$ ) without water addition on the multilayer $\mathrm{PdZn}$ surface alloy on $\mathrm{Pd}$ foil. The temperature program involved a linear ramp $(6.9 \mathrm{~K} / \mathrm{min})$ up to $623 \mathrm{~K}$ followed by isothermal reaction for $21 \mathrm{~min}$.

detected in the stability range of the multilayer alloy. Beyond about $565 \mathrm{~K}, \mathrm{CO}$ started to be formed, due to switching of the surface to the more Pd-like "monolayer" alloy state. According to related theory work $[11,16]$, the $\mathrm{Cu}$-like electronic structure of the $\mathrm{PdZn}$ valence band is important for the selective control of the entire series of dehydrogenation steps, leading from methanol to CO. In particular, the PdZn 1:1 alloy was predicted to stabilize formaldehyde and suppress its further dehydrogenation toward formyl $-\mathrm{CHO}$ and finally $\mathrm{CO}$ (on $\mathrm{Pd}, \mathrm{CH}_{\mathrm{x}}$ species induce a similar stabilization $[32,40])$. Our experiment 
strongly supports this concept, since formaldehyde formation is predominant in the stability range of the multilayer PdZn surface alloy. Once this state decays, the selectivity shifts toward $\mathrm{CO}$. From the negative formation rate of $\mathrm{CH}_{2} \mathrm{O}$ (consumption of intermediate gas phase formaldehyde in the closed batch reactor system) above $\sim 600 \mathrm{~K}$ we can even deduce that $\mathrm{CH}_{2} \mathrm{O}$ (gas) is the key intermediate toward $\mathrm{CO}$ formation (note the coincidence of $\mathrm{CH}_{2} \mathrm{O}$ consumption rate maximum (with negative sign) and (positive) $\mathrm{CO}$ formation rate maximum after $29 \mathrm{~min}$ ). We conclude that the observed selectivity shift results from the change of the combined electronic and geometric alloy structure above $565 \mathrm{~K}$ (typical methanol conversion 50\%).

Nevertheless, in the absence of water (in contrast to the MSR experiments of Fig. 8 shown below), the reaction pathway toward $\mathrm{CO}_{2}$ is not available, which is reasonable since the activation of water is required to provide a "source of oxygen" for the further oxidation of any of the surface $\mathrm{C}-1$ oxygenates $\mathrm{CO}_{2}$. In (pure) methanol the oxidized $\mathrm{Zn}(\mathrm{OH})$ component in the $\mathrm{Zn} 3 \mathrm{~d}$ spectra $(\sim 11.5 \mathrm{eV})$ was also absent, even when the spectra were acquired at a photon energy of $130 \mathrm{eV}$ to increase the surface sensitivity (not shown).

Methanol dehydrogenation on PdZn multilayers was also examined by PM-IRAS. Figure 7 (upper panel) shows spectra acquired at room temperature in $5 \mathrm{mbar} \mathrm{CH}_{3} \mathrm{OH}$, comparing $\mathrm{Pd}(111)$ and $\mathrm{PdZn}(111) / \mathrm{Pd}(111)$. On the $\mathrm{Pd}$ surface, methanol was in part decomposed via $\mathrm{CH}_{2} \mathrm{O}$ to $\mathrm{CO}$, producing hollow-bonded $\mathrm{CO}$ (characterized by the peak at $1873 \mathrm{~cm}^{-1}$, indicative of $\sim 0.4 \mathrm{ML}$ coverage). As reported in $[32,40,42]$ this leads, together with the parallel formation of surface $\mathrm{CH}_{\mathrm{x}}$ species, to a self-poisoning of the process at low temperature. On PdZn, no methanol dehydrogenation occurred at $300 \mathrm{~K}$.

When the reaction temperature was increased (Fig. 7 lower panel), methanol was in part dehydrogenated to CO. However, due to the low binding energy of $\mathrm{CO}$ to $\mathrm{PdZn}$, adsorbed $\mathrm{CO}$ could not be detected during the reaction (note that for Pd surfaces, CO resulting from methanol decomposition can be easily observed at $423 \mathrm{~K}$ [43], However, the product $\mathrm{CO}$ could be detected after cooling the model catalysts to room temperature in the gas. The observed CO frequency was then characteristic of the surface state of PdZn, i.e. up to reaction temperatures $<600 \mathrm{~K}$ the typical $2070 \mathrm{~cm}^{-1}$ peak characterized the PdZn multilayer, whereas upon reaction at $>600 \mathrm{~K}$ the PdZn multilayer decomposed and $\mathrm{CO}$ resonances typical of $\mathrm{Zn}$-lean $\mathrm{PdZn}$ or of developing Pd patches/islands were observed after cooling. For example, after methanol dehydrogenation at 623 $\mathrm{K}$, cooling to $300 \mathrm{~K}$ in the gas yielded a spectrum with peaks at $2070 \mathrm{~cm}^{-1}$ (still characteristic of PdZn) and at 1918 $\mathrm{cm}^{-1}$ (characteristic of bridging/hollow CO on Pd(111) [40] and/or of Zn-lean PdZn [44]). Intermediate species of methanol dehydrogenation such as $\mathrm{CH}_{2} \mathrm{O}$ could not be detected (the peak at $1034 \mathrm{~cm}^{-1}$ is due to the $\mathrm{C}-\mathrm{O}$ stretching vibration of gas phase methanol), due to a presumably too small steady-state concentration below $565 \mathrm{~K}$ and its decomposition above $565 \mathrm{~K}$. In addition, the $\mathrm{Pd}(111)$ single
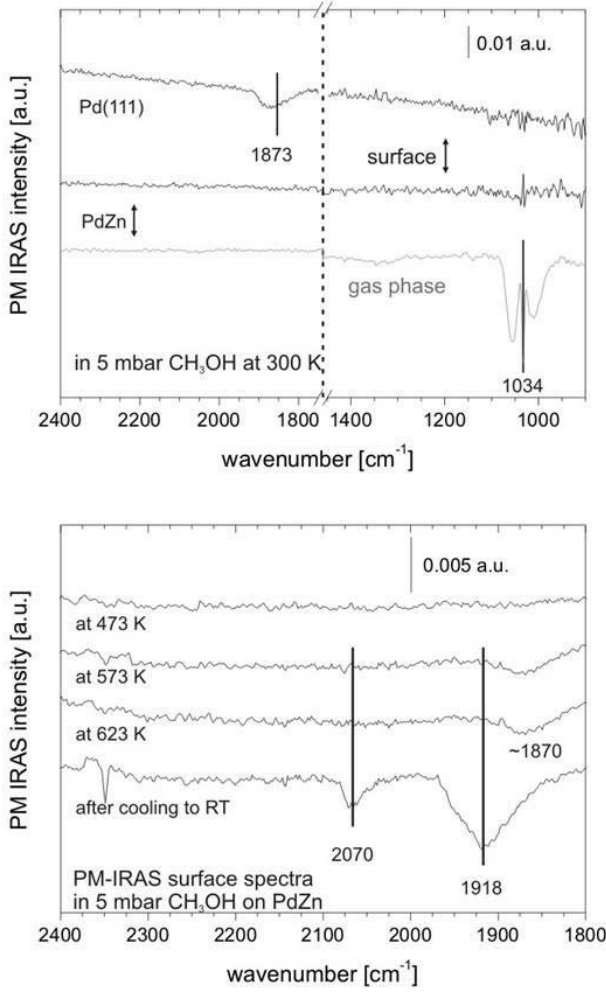

Fig. 7: PM-IRAS spectra of surface and gas phase species, acquired during and after methanol reaction on the $\mathrm{PdZn}$ multilayer alloy on $\operatorname{Pd}(111)$.

crystal used for PM-IRAS was $<1 \mathrm{~cm}^{2}$ so that the expected amount of $\mathrm{CH}_{2} \mathrm{O}$ is much smaller than for Pd foil in the allglass reactor.

\subsection{MSR on clean Pd vs. "monolayer" vs. "multi- layer" PdZn surface alloy}

In a recent publication [14], the MSR catalytic performance of the $630 \mathrm{~K}$ annealed subsurface-Zn-lean "monolayer" surface alloy was compared with that of clean Pd foil under otherwise identical experimental conditions.

Both samples were characterized before reaction by LEIS confirming the $\sim 1: 1 \mathrm{Pd}: \mathrm{Zn}$ ratio of the $2 \mathrm{D}$ alloy surface (after annealing $3 \mathrm{ML} \mathrm{Zn}$ deposit to $623 \mathrm{~K}$; cf. Figs.2), and the absence of $\mathrm{Zn}$ on clean Pd. On both types of surfaces $\mathrm{CO}$ was the only reaction product observed during the temperature-programmed reaction, whereas $\mathrm{CH}_{2} \mathrm{O}$ remained below the detection limit throughout the whole temperature range. Despite the presence of 0.24 mbar water in the gas phase, $\mathrm{CO}_{2}$ was also not detected. LEIS performed after the reaction showed an only slightly changed $\mathrm{Pd}: Z n$ ratio of 56:44, i.e. the "monolayer" alloy exhibited high thermochemical stability. Moreover, the in-situ Zn3d + VB spectra did not change during MSR (and are thus not shown) and did also not indicate any water-induced 


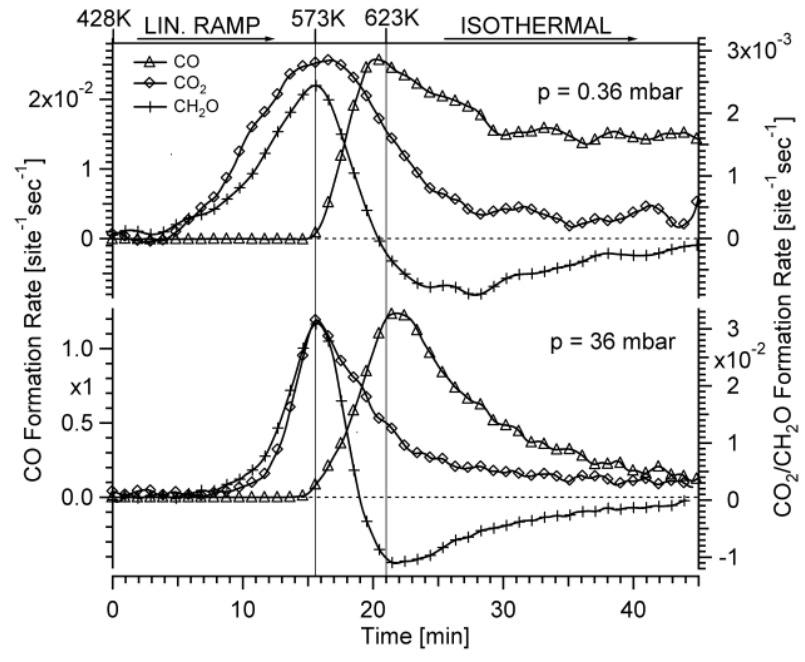

Fig. 8: MSR temperature programmed reaction on the multilayer PdZn alloy on Pd foil (3ML Zn annealed at 503K for $5 \mathrm{~min}$ ). The reaction conditions for the high pressure reaction were $12 \mathrm{mbar}$ methanol +24 mbar water, and for the low pressure reaction 0.12 mbar +0.24 mbar, in both cases diluted in 1 bar He inert gas to ensure reliable gas recirculation. The temperature program involved a linear ramp $(9.3 \mathrm{~K} / \mathrm{min})$ up to $623 \mathrm{~K}$ followed by isothermal reaction for $24 \mathrm{~min}$ (viewgraph was extracted from supporting information of ref. 14]).

$\mathrm{Zn}(\mathrm{OH})$ component at $\sim 10.5 \mathrm{eV}$. This clearly shows that the "monolayer" alloy is apparently not capable of activating water as efficiently as the "multilayer" surface alloy state, even though the "multilayer-to-monolayer" change in the Pd:Zn surface ratio is small in between $\sim 573$ and 623 K. Possibly, water activation is suppressed by the more Pdlike electronic structure of the "monolayer" alloy surface, despite the presence of suitable Pd-Zn surface ensembles (but this awaits theoretical confirmation).

The absence of the final product $\mathrm{CO}_{2}$ can therefore be rationalized by the lack of the required "source of oxygen" both on PdZn monolayer and Pd. For the same reason, clean Pd metal is well known to be an excellent methanol dehydrogenation catalyst but with hardly any activity in $\mathrm{CO}_{2}$-selective MSR. The strong catalyst deactivation observed after reaching the final temperature of $623 \mathrm{~K}$ after $\sim 15$ min could be rationalized by ex-situ AES and XPS carbon spectra recorded after the MSR experiment, showing increasing amounts of carbon deposits progressively blocking the active metal surface with increasing reaction time [42]. Moreover, the experiments were all performed in a re-circulating batch reactor, with the consequence of decreasing reactant pressures over time, which also contributes to the isothermal rate decrease of product formation with time.

Finally, temperature-programmed MSR experiments were carried out on the most promising "multilayer" alloy state prepared by thermal annealing of 3 ML Zn on Pd foil at $503 \mathrm{~K}$ for $5 \mathrm{~min}$ (Fig. 8). The reason for the comparison of the "low- and high-pressure" experiments in Fig. 8 was to connect the batch reactor studies ( 36 mbar) with the experimental conditions chosen for the corresponding insitu XPS experiment at HZB/BESSY II (see Fig. 9), which was limited in total pressure to about- $0.36 \mathrm{mbar}$. The analogous 0.36 and 36 mbar experiments in the all-glass HP cell in Innsbruck allowed us to establish an unambiguous correlation between the catalytic and spectroscopic measurements performed in the two different systems. In fact, Fig. 8 shows no substantial "pressure gap" effect between 0.36 mbar and 36 mbar total reactant pressure, when using the same MeOH:water pressure ratio.

For the MSR reaction mixture, the temperature region of $\mathrm{CH}_{2} \mathrm{O}$ formation and of the selectivity change from $\mathrm{CH}_{2} \mathrm{O}$ toward $\mathrm{CO}$ is well comparable to the experiment of Fig. 6 with (pure) methanol. The main difference is the much higher $\mathrm{CO}_{2}$ fraction in the products, likely because the reaction channel from $\mathrm{C}_{1}$-oxygenates toward $\mathrm{CO}_{2}$ was now available due to the activation of water. Whereas $\mathrm{CH}_{2} \mathrm{O}$ was formed and then again consumed by transformation to $\mathrm{CO}$ (negative reaction rate of $\mathrm{CH}_{2} \mathrm{O}$ coincided again with positive $\mathrm{CO}$ formation rate at $\sim 22 \mathrm{~min}$ ), revealing its intermediate nature, $\mathrm{CO}_{2}$ was a final product. Again, deactivation of the catalyst in the isothermal part of the experiment occurred via progressive carbon deposition at $630 \mathrm{~K}$, as verified by the decreasing $\mathrm{CO}$ formation rate and postreaction carbon AES spectra.

The results of Fig. 8 imply that formaldehyde is the key intermediate toward $\mathrm{CO}_{2}$ at least up to $\sim 573 \mathrm{~K}$, but starts to act as an intermediate toward $\mathrm{CO}$ once the transition from the multi- to the monolayer alloy has started, in the sense that intermediate $\mathrm{CH}_{2} \mathrm{O}$ in already desorbed to the gas phase becomes later-on dehydrogenated to $\mathrm{CO}$ by readsorption and reaction at higher temperatures, i.e. on the more Pd-like "monolayer"-alloy state of the surface.

A mechanistic model of the MSR reaction in the stability range of the multilayer alloy up to $573 \mathrm{~K}$ should therefore not only involve the suppression of $\mathrm{CH}_{2} \mathrm{O}$ dehydrogenation to $\mathrm{CO}$, resulting from the particular electronic surface structure of the PdZn multilayer, but should also account for efficient water activation on this surface, yielding e.g. OH(ads) at $\mathrm{Zn}$ sites. The resulting "oxygen donor" surface species, e.g. $\mathrm{ZnOH}$, is then capable of fully oxidizing at least a part of the surface-adsorbed $\mathrm{CH}_{2} \mathrm{O}$. As some form of surface-bonded formaldehyde may either become quickly oxidized by interaction with the observed $\mathrm{Zn}-\mathrm{O}(\mathrm{H})$ species or-is simply thermally desorbed to the gas phase, the relative probabilities of thermal desorption as competing "chemical reaction" to total oxidation will determine the product partial pressure ratio. If the overall rate-limiting step is located within the dehydrogenation steps prior to formaldehyde, both the subsequent formaldehyde desorption and total oxidation pathways should be much faster, which can explain the observed simultaneous formation of $\mathrm{CO}_{2}$ and $\mathrm{CH}_{2} \mathrm{O}$ up to $573 \mathrm{~K}$. This scenario is supported by Ranganathan et al. [37], who reported a faster conversion of formaldehyde than methanol toward $\mathrm{CO}_{2}$ under otherwise identical reaction conditions. Moreover, the reaction probability toward $\mathrm{CO}_{2}$ appears to be much higher on the supported $\mathrm{PdZn} / \mathrm{ZnO}$ systems, which may be attributed to 


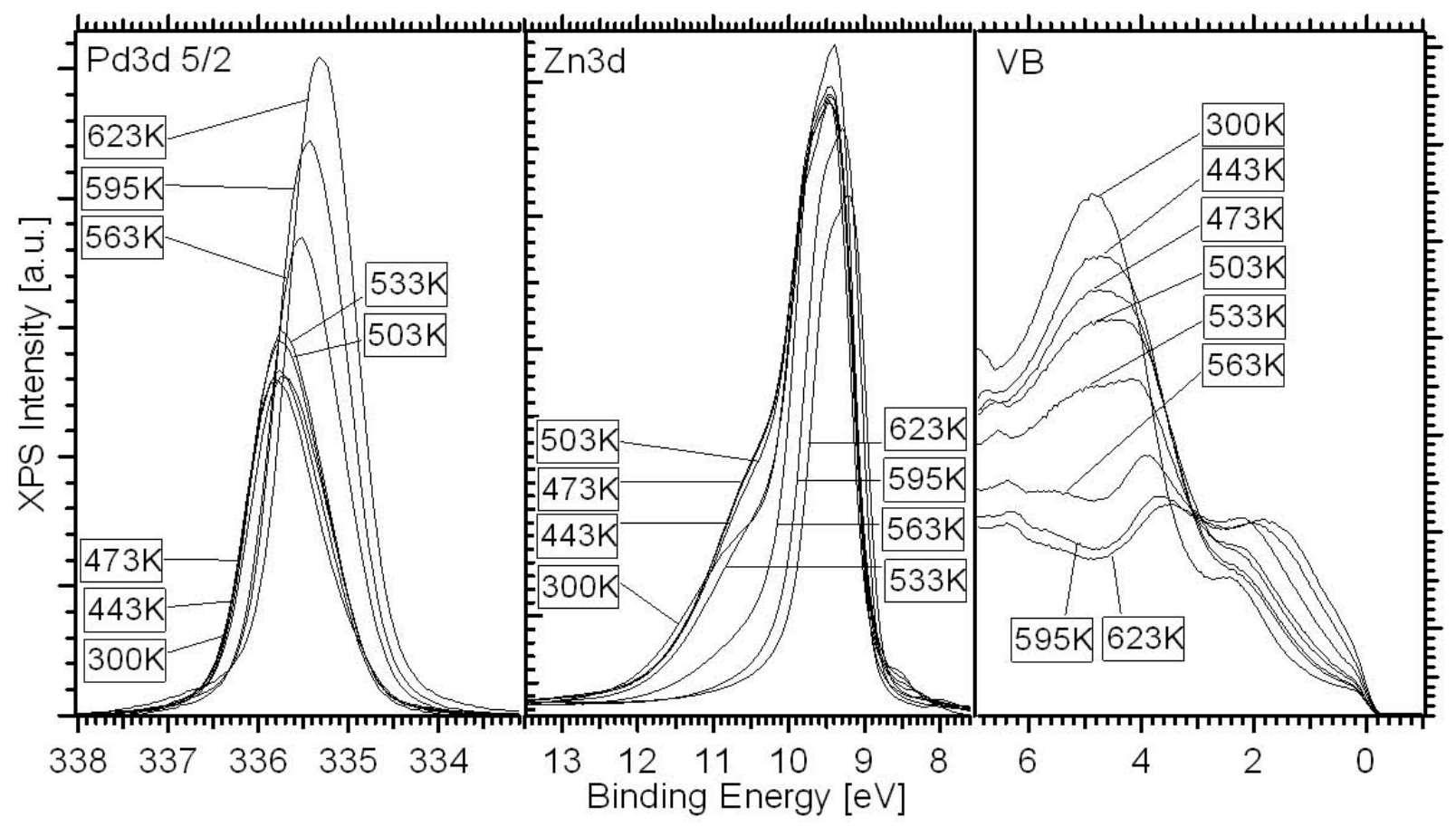

Fig. 9: $\mathrm{Pd} 3 \mathrm{~d}_{5 / 2}$ core level spectra (left), $\mathrm{Zn} 3 \mathrm{~d}$ spectra (middle) and VB spectra (right) obtained in-situ during methanol steam reforming (0.12 mbar $\mathrm{MeOH}+0.24 \mathrm{mbar}_{2} \mathrm{O}$ ) on the multilayer surface alloy (3ML $\mathrm{Zn}$ on $\mathrm{Pd}(111)$ annealed to $503 \mathrm{~K}$ in vacuum). Pd $3 \mathrm{~d}$ core level spectra were recorded with $650 \mathrm{eV}$ photon energy, the $\mathrm{VB}$ and $\mathrm{Zn} 3 \mathrm{~d}$ region with $120 \mathrm{eV}$ in order to enhance the surface sensitivity.

the much higher abundance of $\mathrm{ZnO}$ surface or $\mathrm{ZnO} / \mathrm{PdZn}$ interface sites, i.e. the surface chemistry of the support and/or of the metal support interface (especially for efficient water activation) must be considered for $\mathrm{PdZn} / \mathrm{ZnO}$, whereas these sites must be absent on our model surface. Why these sites are more reactive for formaldehyde conversion than the "isolated" PdZn bimetal surface sites is an open question.

On the supported $\mathrm{PdZn} / \mathrm{ZnO}$ catalyst formaldehyde was also suggested as central intermediate, but it could not be detected due to its small steady-state concentration [1]. It was, however, detected indirectly via follow-up products of formaldehyde, such as methyl formate $\mathrm{HCOOCH}_{3}$ (methanol condensation product, high selectivity only in the absence of water at T 473 K).

Also a comparison of "benchmark" turnover rates from the literature on different catalyst systems with the values of Figure 8 may be useful at this point. Iwasa et al.reported a TOF of $0.497 / 3=0.166$ on supported $\mathrm{Pd} / \mathrm{ZnO}$ (division by 3 because turnover is given with respect to $\mathrm{H}_{2}$ formation) at $493 \mathrm{~K}$ [1], whereas Ranganathan et al.find 0.8 at $503 \mathrm{~K}$, again on $\mathrm{Pd} / \mathrm{ZnO}$ [37] and Conant et al. report 0.39 at $523 \mathrm{~K}$, on a comparable supported catalyst [37]. These values are somewhat higher than those reported in this work: we estimate a TOF of $0.01 * 2 * 2=0.04$ at $\sim 540$ $\mathrm{K}$ and a maximum TOF of $0.031 * 2 * 2=0.144$ at $570 \mathrm{~K}$ (assumptions for factor 4: all formaldehyde would become quickly converted toward $\mathrm{CO}_{2}$ on supported catalysts, due to much stronger contribution of $\mathrm{ZnO}$ surface or metal- support interface sites, and $50 \%$ of the original Pd surface atoms (on the clean foil) are available for reaction).

In contrast to the supported catalysts, at $\sim 500 \mathrm{~K}$ our model catalyst surface is hardly active for MSR, possibly because of facilitated water activation on the supported catalysts, and the maximum MSR activity at the highest selectivity for $\mathrm{CO}_{2}$ is approached between 560 and $570 \mathrm{~K}$. Moreover, it seems that most MSR experiments on supported catalysts were done below $\sim 523 \mathrm{~K}$ in order to avoid selectivity losses due to the increasing influence of the inverse water gas shift reaction at higher temperatures, thus no direct comparison at the equivalent temperatures was possible.

Another difference is important, namely the total reactant pressure, which was 36 mbar at maximum in our MSR experiments, but much higher (around 1 bar) in the supported catalyst studies cited above. This is certainly another main reason for the somewhat lower TOF values derived for our model catalyst, but even so we are not far off the "lower end" of the usual values.

We also attempted to estimate an apparent activation energy for the initial increase of the $\mathrm{H}_{2} \mathrm{CO}$ and $\mathrm{CO}_{2}$ formation rates, with the assumptions of a stable surface and hardly any change of methanol concentration up to $573 \mathrm{~K}$. We calculated an apparent $\mathrm{E}_{\mathrm{a}}$ of around $1 \mathrm{eV}$ for the initial $\mathrm{CO}_{2}$ formation between 510 and $560 \mathrm{~K}$ (with a large error bar of at least $\pm 20 \%$ ), which may be compared to recent DFT work e.g. by Y. Huang et al. [37], reporting an absolute value of $0.91 \mathrm{eV}$ for the most likely rate determining methoxy formation from methanol on a bilayered PdZn 

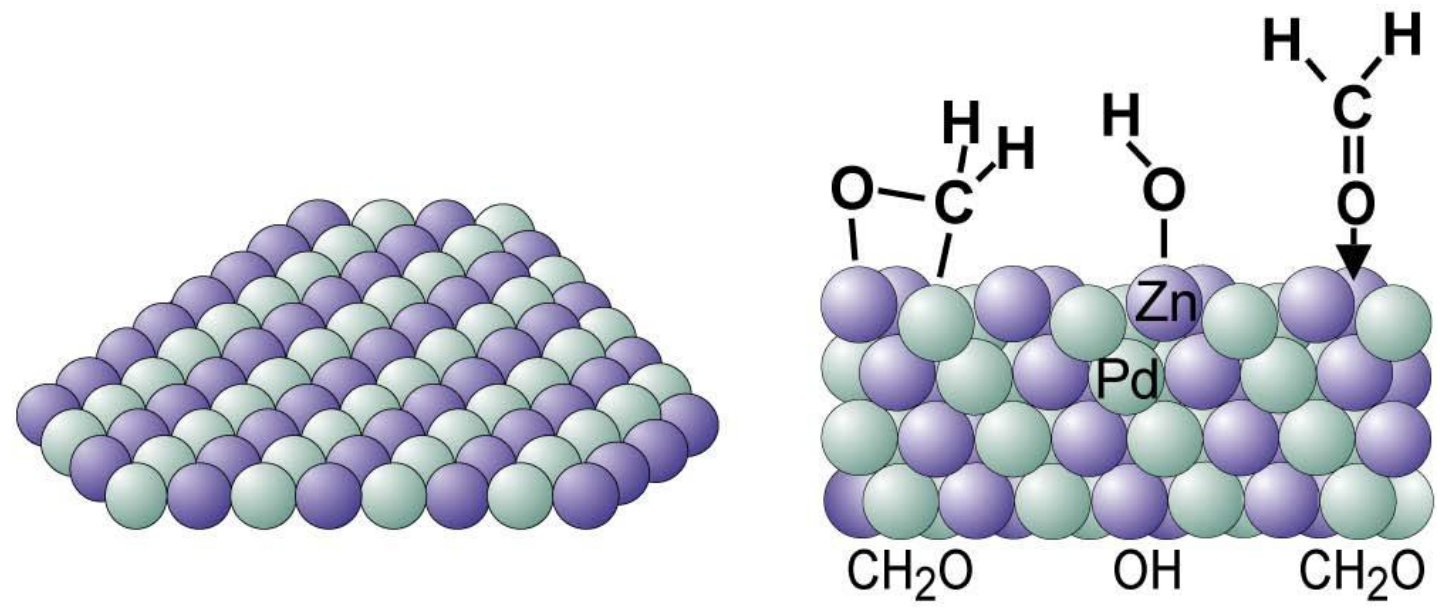

Fig. 10: Left: $\mathrm{p}(2 \mathrm{x} 1)$ surface structure of the 1:1 multilayer PdZn alloy on $\mathrm{Pd}(111)$. Right: side view of the multilayer PdZn alloy with likely surface intermediates reacting toward $\mathrm{CO}_{2}$ (viewgraph was extracted from supporting information of ref. 14]).

1:1 surface alloy. Of course, as always with absolute energies from DFT, e.g. the zero point energy corrections and other computational assumptions make a big difference, so one has to be cautious with such comparisons.

The XPS spectroscopic fingerprints associated with MSR on the (initially present) $503 \mathrm{~K}$ multilayer PdZn surface alloy on $\operatorname{Pd}(111)$ at 0.36 mbar total reactant pressure are shown in Fig 9. The decomposition of the PdZn multilayer alloy occurs above $573 \mathrm{~K}$, as expected from the thermal and thermochemical stability measurements, which again manifests itself by the shift of $\mathrm{Pd} 3 \mathrm{~d}_{5 / 2}$ towards lower BEs (Fig. 9, left panel) and by the transformation of the VB from the "Cu-like" to the "Pd-like" density of states. According to the related kinetic measurements of Fig. 8, at this temperature CO formation sets in. Despite the formation of the surface-limited $\mathrm{ZnOH}$ species, the $\mathrm{Zn}$-rich alloy remained stable up to $573 \mathrm{~K}$. The oxidized state of $\mathrm{Zn}$, which can be seen as a shoulder at $\sim 10.5 \mathrm{eV}$ of the main $\mathrm{Zn}$ $3 \mathrm{~d}$ peak (Fig. 9, middle panel) is present already at the lowest temperature, but only stable up to $\sim 573 \mathrm{~K}$, i.e. once the stability limit of the multilayer alloy was exceeded, the related $\mathrm{ZnOH}$ species also became unstable.

These spectral series illustrates the cooperative, bifunctional action of the lowered DOS near the Fermi edge and the water activation by the PdZn surface ensembles. At the maximum of $\mathrm{CH}_{2} \mathrm{O} / \mathrm{CO}_{2}$ selectivity, the effects of suppressing the " $\mathrm{CH}_{2} \mathrm{O}$ to $\mathrm{CO}$ pathway" by the still prevailing multilayer alloy electronic structure and the oxidised $\mathrm{Zn}$ species, likely the source of oxygen for the reaction of $\mathrm{C} 1$ oxygenates toward $\mathrm{CO}_{2}$, combine in a unique manner. Experimentally, the mechanistic role of the $\mathrm{ZnOH}$ species was additionally corroborated by water treatment of the surface (see Fig. 3) followed by testing of the reducibility of the $\mathrm{ZnOH}$ species in different gases $\left(\mathrm{H}_{2}\right.$, methanol, $\left.\mathrm{CO}\right)$. At around $560-570 \mathrm{~K}$ there are different ways to suppress the $\mathrm{ZnOH}$ intensity in the $\mathrm{Zn} 3 \mathrm{~d}$ region: exposure to methanol or hydrogen after water oxidation, or also switching off the water partial pressure during MSR. The $\mathrm{ZnOH}$ species can in turn be reversibly populated by switching from clean methanol to the MSR mixture or to clean water.

The Pd 3d and VB results shown in Fig. 9 are complemented well by the related $\mathrm{C} 1 \mathrm{~s}$ spectra of ref [14] (supporting information). The presence of $\mathrm{CH}_{2} \mathrm{O}$ or related oxygenates on the surface was observed therein in the temperature range up to $505 \mathrm{~K}$. Around $573 \mathrm{~K}$, the surface $\mathrm{CH}_{2} \mathrm{O}$ is was replaced by $\mathrm{CO}$. It was concluded that gas phase $\mathrm{CH}_{2} \mathrm{O}$ is formed just in between 505 and $573 \mathrm{~K}$ by desorption of the related surface species, whereas formation and desorption of $\mathrm{CO}$ takes place above $573 \mathrm{~K}$, once the "monolayer" alloy state starts to develop. PM-IRAS spectra of MSR did not yield further information yet.

\subsection{Surface chemistry on $P d Z n$ during MSR}

At this stage it becomes clear that previous ideas for selective MSR, involving full methanol dehydrogenation followed by $\mathrm{CO}$ conversion to $\mathrm{CO}_{2}$ via the water gas shift reaction, are not applicable to the PdZn alloy system. On the basis of kinetic studies in micro-channel reactors Pfeifer et al. [45] have shown that methyl formate is unlikely the main sequential intermediate toward $\mathrm{CO}_{2}$. It rather represents a by-product resulting from the reaction of formate species with a sufficient amount of coadsorbed methanol, i.e. when little water is present, as also concluded from [1].

The central role of formaldehyde is apparent from the present experiments, which leads us to the question of the local structural and molecular chemistry responsible for selective $\mathrm{CO}_{2}$ formation. Fig. 10 shows a schematic drawing of the 1:1 Pd:Zn surface alloy with its well established $\mathrm{p}(2 \mathrm{x} 1)$ surface structure $[5,6,34,36]$, along with the most likely intermediates toward $\mathrm{CO}_{2}$. 
In analogy to $\mathrm{Cu}$ surfaces, Iwasa et al. suggested that aldehydes on the PdZn alloy are preferentially adsorbed and stabilized in the $\eta^{1}(\mathrm{O})$-structure (bonding via oxygen, right side), while they rather exist as $\eta^{2}(\mathrm{C}, \mathrm{O})$-structure (left side) on metallic Pd and Pt. On clean Pd these " $\mathrm{C}-\mathrm{O}$ bond weakened" aldehyde species more easily undergo transformation to carbonaceous deposits via $\mathrm{C}-\mathrm{O}$ bond scission, but also decarbonylation to carbon monoxide and hydrogen $[1,11,33]$. Both forms of formaldehyde have been detected by Jeroro et al. using HREELS [46], coexisting after formaldehyde adsorption on the PdZn surface in the temperature region $150-200 \mathrm{~K}$, whereby a trend toward the $\eta^{1}(\mathrm{O})$ structure was observed at higher $\mathrm{Zn}$ loadings of $\operatorname{Pd}(111)$. Nevertheless, a clear assessment of higher reactivity to either species was not possible. DFT calculations favoured a top-bridge-top (tbt) configuration with the $\mathrm{C}$ and $\mathrm{O}$ atoms each bridging two substrate atoms, i.e. a $\eta^{2}(\mathrm{C}, \mathrm{O})$-structure of rather weakly adsorbed formaldehyde. The elementary step of formaldehyde dehydrogenation starts from this species and is similar on $\mathrm{Pd}(111), \mathrm{Cu}(111)$ and also $\mathrm{PdZn}(111)$, whereby the barriers on $\mathrm{PdZn}$ and $\mathrm{Cu}$ are significantly higher $[11,16]$. A thermodynamic analysis of coupled water dissociation equilibria involving $\mathrm{H}(\mathrm{ads})$, $\mathrm{OH}$ (ads) and $\mathrm{O}$ (ads), based on DFT-derived free surface energies, was presented in [11,17] as well. Accordingly, at a given water pressure of $\sim 1 \mathrm{~atm}$ at $\sim 500 \mathrm{~K}$, combined with hydrogen pressures in the range $10^{-6}-1 \mathrm{~atm}$ (being realistic $\mathrm{H}_{2}$ background pressures during MSR), the dominant oxygen-containing surface species on the PdZn alloy was $\mathrm{OH}(\mathrm{ads})$ rather than $\mathrm{O}$ (ads)

At present, open mechanistic questions are rather related to the elementary reaction steps, starting out from coadsorbed formaldehyde and water species, and finally ending with the desorption of $\mathrm{CO}_{2}$ and $\mathrm{H}_{2}$. Assuming the reactive species being the dominant $\mathrm{OH}(\mathrm{ads})$ at 3 -fold hollow sites (with a larger coordination of $\mathrm{Zn}$ atoms; as calculated in [17]) and $\eta^{2}$ formaldehyde in tbt configuration, a mechanism already qualitatively suggested by Takezawa and Iwasa [47] and Takahashi et al. [48] for a $\mathrm{Cu} / \mathrm{SiO}_{2}$ catalyst could possibly proceed via a dioxomethylene species originating from the addition of surface hydroxyls to adsorbed formaldehyde. Dioxomethylene, also the intermediate of the reverse methanol synthesis reaction, is then supposed to dehydrogenate to a formate group. Metallic surfaces generally favor decarboxylation of formates, which would finally result in $\mathrm{CO}_{2}$ (gas) and additional $\mathrm{H}(\mathrm{ads})$, the latter finally desorbing associatively to $\mathrm{H}_{2}$ (gas). Nevertheless, recent attempts to verify this mechanistic

\section{References}

[1] a) A. Szizybalski, F. Girgsdies, A. Rabis, Y. Wang, M. Niederberger, T. Ressler, J. Catal. 233 (2005) 297; b) N. Iwasa, N. Takezawa, Top. Catal. 22 (2006) 215

[2] S. Penner, B. Jenewein, H. Gabasch, B. Klötzer, D. Wang, A. Knop-Gericke, R. Schlögl, K. Hayek, J. Catal. 241 (2006) 14.

[3] J.D. Holladay, Y. Wang, E. Jones, Chem. Rev. 104 ( 2004) 4767. picture by DRIFTS spectroscopy on $\mathrm{Cu}$ catalysts were unsuccessful [49]. On PdZn this mechanism is not supported by spectroscopic information, too, and has to be considered as speculative at present.

\section{Conclusions}

A thermal/thermochemical stability limit of up to 573 $\mathrm{K}$ has been verified for the MSR $\left(\mathrm{CO}_{2}\right)$-selective $\mathrm{PdZn}$ multilayer alloy phase on $\operatorname{Pd}(111)$ and Pd-foil via thermal annealing experiments in vacuum, mbar pressure of water, methanol, $\mathrm{CO}$, and under MSR reaction conditions. Up to this limit the PdZn multilayer alloy model catalyst maintained the predicted $\mathrm{Cu}$-like electronic structure of the valence band even under realistic MSR conditions. Consequently, the dissociation barrier between $\mathrm{CH}_{2} \mathrm{O}$ and $\mathrm{CHO}$ was higher than for pure $\mathrm{Pd}$, thus leading to increased formation of formaldehyde in the gas phase, which we were able to verify experimentally as the central intermediate. The theory-predicted control of dehydrogenation steps of $\mathrm{CH}_{2} \mathrm{O}$ could not only be confirmed, but moreover the importance of effective total oxidation of $\mathrm{CH}_{2} \mathrm{O}$ by activated water at oxidized $\mathrm{Zn}$ sites on the PdZn catalyst surface could be proven experimentally. The formation of $\mathrm{CH}_{2} \mathrm{O}$ and $\mathrm{CO}_{2}$ at reactive bifunctional $\mathrm{PdZn}$ surface ensembles exhibiting a $\mathrm{Cu}$-like local density of states can be explained on the basis of formaldehyde as common surface intermediate either desorbing to the gas phase or becoming oxidized by $\mathrm{Zn}-\mathrm{OH}$ species.

\section{Acknowledgements}

This work was financially supported by the Austrian Science Fund through grant P208920-N19 and by TU Vienna via IP 2008 VSFG. Ch. Rameshan acknowledges a PhD scholarship granted by the Max Planck Society. Support for the measurements at HZB/BESSY II was granted through EU program RII3-CT-2004-506008, proposal No. 2008_2_80336. The authors thank the BESSY staff for their support of the in situ XPS measurements.
[4] M. Lenarda, E. Moretti, L. Storaro, P. Patrono, F. Pinzari, E. Rodriguez-Castellon, A. Jimenez-Lopez, G. Busca, E. Finocchio, T. Montanari, R.Frattini, Appl. Catal. A 312 (2006) 220.

[5] A. Bayer, K. Flechtner, R. Denecke, H.-P. Steinrück, K. H. Neyman, N. Rösch, Surf. Sci. 600 (2005) 78. 
[6] H. Gabasch, S. Penner, B. Jenewein, B. Klötzer, A. KnopGericke, R. Schlögl, K. Hayek, J. Phys. Chem. B 110 (23) (2006) 11391

[7] J. A. Rodriguez, Progress in Surface Science 81 (2006) 141.

[8] Z. Chen, K. M. Neyman, N. Rösch, Surf. Sci. 548 (2004) 291.

[9] K. M. Neyman, R. Sahnoun, C. Inntam, S. Hengrasmee, N. Rösch, J. Phys. Chem. B 108 (2004) 5424

[10] Z. Chen, K. M. Neyman, A.B. Gordienko, N. Rösch, Phys. Rev. B 68 (2003) 075417.

[11] K. M. Neyman, K.H. Lim, Z.-X. Chen, L.V. Moskaleva, A. Bayer, A. Reindl, D. Borgmann, R. Denecke, H.-P. Steinrück, N. Rösch, PCCP 9(27) (2007) 3470.

[12] W. Stadlmayr, Ch. Rameshan, Ch. Weilach, H. Lorenz, M. Hävecker, R. Blume, T. Rocha, D. Teschner, A. KnopGericke, D. Zemlyanov, S. Penner, R. Schlögl, G. Rupprechter, B. Klötzer, N. Memmel, J. Phys. Chem. C 114 (2010) 10850

[13] A.-P. Tsai, S. Kameoka, Y. Ishii, J. Phys. Soc. Jap. 73 (2004) 3270 .

[14] Ch. Rameshan, W. Stadlmayr, C. Weilach, S. Penner, H. Lorenz, M. Hävecker, R. Blume, T. Rocha, D. Teschner, A. Knop-Gericke, R. Schlögl, N. Memmel, D. Zemlyanov, G. Rupprechter, B. Klötzer, Angew. Chem. Int. Ed. 49 (2010) 3224.

[15] P. Bera, J.M. Vohs, J. Phys. Chem. C 111(19) (2007) 7049.

[16] K. H. Lim, Z. X. Chen, K. M. Neyman, N. Rösch, J. Phys. Chem. B, 110 (2006) 14890.

[17] K. H. Lim, L. Moskaleva, N. Rösch, ChemPhysChem 7 (2006) 1802.

[18] N. Schumacher, A. Boisen, S. Dahl, A.A. Gokhale, S. Kandoi, L.C. Grabow, J.A. Dumesic, M. Mavrikakis and I. Chorkendorff, J. Catal. 229 (2005) 265.

[19] O. Dulub, B. Meyer, U. Diebold, Phys. Rev. Lett. 95 (2005) 136101.

[20] M. A. Henderson, Surf. Sci. Rep. 46 (2002) 1.

[21] C. T. Au, J. Breza, M. W. Roberts, Chem. Phys. Lett. 66 (1979) 340

[22] B. J. Hinch, L. H. Dubois, J. Chem. Phys. 96 (1992) 3262.

[23] A. F. Carley, P. R. Davies, M. W. Roberts, N. Shukla, Y. Song, K. K. Thomas, Appl. Surf. Sci. 81 (1994) 265.

[24] A. Neramittagapong, S. Hoshino, T. Mori, J. Kubo, Y. Morikawa, Chem. Lett. 11 (2002) 1078.

[25] J. Pantförder, S. Pöllmann, J.F. Zhu, D. Borgmann, R. Denecke, H.-P. Steinrück, Rev. Sci. Instrum. 76 (2005) 014102.

[26] Y. Suwa, S. Ito, S. Kameoka, K. Tomishige, K. Kunimori, Appl. Catal. A 267 (2004) 9.

[27] W. Reichl, G. Rosina, G. Rupprechter, C. Zimmermann, K. Hayek, Rev. Sci. Instrum. 71(3) (2000) 1495.

[28] H. Bluhm, M. Hävecker, A. Knop-Gericke, E. Kleimenov, R. Schlögl, D. Teschner, V.I. Bukhtiyarov, D.F. Ogletree, M. Salmeron, J. Phys. Chem. B 108 (2004) 14340.
[29] G. Rupprechter, C. Weilach, J. Phys. Condens. Matter 20 (2008) 184020

[30] D. Zemlyanov, B. Aszalos-Kiss, E. Kleimenov, D. Teschner, S. Zafeiratos, M. Hävecker, A. Knop-Gericke, R. Schlögl, H. Gabasch, W. Unterberger, K. Hayek, B. Klötzer, Surf. Sci. 600 (2006) 983.

[31] H. Gabasch, W. Unterberger, K. Hayek, B. Klötzer, E. Kleimenov, D. Teschner, S. Zafeiratos, M. Hävecker, A. Knop-Gericke, R. Schlögl, B. Aszalos-Kiss, D. Zemlyanov, Surf. Sci. 600 (2006) 2980.

[32] M. Borasio, O. Rodríguez de la Fuente, G. Rupprechter, H.-J. Freund, J. Phys. Chem. B Letters 109 (2005) 17791.

[33] G. Rupprechter, Advances in Catalysis 51 (2007) 133

[34] G. Weirum, M. Kratzer, H.-P. Koch, A. Tamtögl, J. Killmann, I. Bako, A. Winkler, S. Surnev, F.P. Netzer, R. Schennach, J. Phys. Chem. C 113(22) (2009) 9788.

[35] M. Kratzer, A. Tamtögl, J. Killmann, R. Schennach, A. Winkler, Appl. Surf. Sci. 255(11) (2009) 5755.

[36] W. Stadlmayr, S. Penner, B. Klötzer, N. Memmel, Surf. Sci. 603(1) (2009) 251

[37] T. Conant, A.M. Karim, V. Lebarbier, Y. Wang, F. Girgsdies, R. Schlögl, A. Datye, J. Catal. 257 (2008) 64; E. S. Ranganathan, S. K. Bej, L. T. Thompson, Appl. Catal. A 289 (2005) 153; Y. Huang, Z.X. Chen, Langmuir 26(13) (2010) 10796

[38] H. Unterhalt, G. Rupprechter, H.-J. Freund, J. Phys. Chem. B. 106 (2002) 356

[39] G. Rupprechter, H. Unterhalt, M. Morkel, P. Galletto, L. Hu, H.-J. Freund, Surf. Sci. 502-503 (2002) 109.

[40] G. Rupprechter, Adv. Catal. 51 (2007) 133

[41] A.Tamtögl, M. Kratzer, J. Killman, A. Winkler, J. Chem. Phys. 129 (2008) 224706

[42] M. Morkel, V. V. Kaichev, G. Rupprechter, H.-J. Freund, I. P. Prosvirin, V. I. Bukhtiyarov, J. Phys. Chem B 108 (2004) 12955.

[43] M. Bäumer, J. Libuda, K. M. Neyman, N. Rösch, G. Rupprechter, H.-J. Freund, Phys. Chem. Chem. Phys. 9 (2007) 3541

[44] I. Bako, R. Schennach, G. Palinkas, Journal of Physics: Conference Series 100 (2008) 052067

[45] P. Pfeifer, A. Kölbl, K. Schubert, Catalysis Today 110 (2005) 76.

[46] E. Jeroro, J.M. Vohs, J. Am. Chem. Soc. 130 (2008) 10199.

[47] N. Takezawa, N. Iwasa, Catal. Today 36 (1997) 45.

[48] K. Takahashi, N. Takezawa, H. Kobayashi, Appl. Catal. 2(6) (1982) 363.

[49] B. Frank, F.C. Jentoft, H. Soerijanto, J. Kröhnert, R. Schlögl, R. Schomäcker, J. Catal. 246 (2007) 177. 